\title{
A JUDICIARIZAÇÃO DA POLÍTICA COMO INSTRUMENTO DE CONTENÇÃO DA DEGRADAÇÃO POPULISTA DA LEGITIMIDADE DEMOCRÁTICA ${ }^{1}$
}

\author{
THE JUDICIALIZATION OF POLITICS AS AN INSTRUMENT FOR CONTAINING POPULIST \\ DEGRADATION OF DEMOCRATIC LEGITIMACY
}

Orlando Villas Bôas Filho*

\begin{abstract}
Resumo:
Este artigo pretende analisar o processo de judiciarização, tal como definido na "sociologia política do direito" proposta por Jacques Commaille, como instrumento de contenção da degradação populista da legitimidade democrática. Para tanto, realiza, em primeiro lugar, uma apresentação geral, sem pretensão de distanciamento crítico, da "sociologia política do direito" para, a partir dela, enfocar a questão da judiciarização. Em seguida, é mobilizada a tese de Pierre Rosanvallon acerca da complexificação da experiência democrática contemporânea que conduz à consideração de novas formas de legitimidade (imparcialidade, proximidade e reflexividade). Por fim, é feita uma breve reconstrução das características atribuídas por Rosanvallon ao fenômeno do populismo para, a partir daí, analisar como a degradação da legitimidade democrática por ele engendrada pode ser contida pela judiciarização.

Palavras-chave: Judiciarização. Legitimidade. Populismo. Democracia. Sociologia Política do Direito.
\end{abstract}

\begin{abstract}
:
This paper aims to analyze the process of judicialization, as defined in the "political sociology of law" proposed by Jacques Commaille, as an instrument to contain the populist degradation of democratic legitimacy. To do so, it makes initially a general presentation, without pretension of critical distance, of the "political sociology of law" to focus on the question of judicialization. Then, Pierre Rosanvallon's thesis about the complexification of contemporary democratic experience that leads to the consideration of new forms of legitimacy (impartiality, proximity and reflexivity) is mobilized. Finally, a brief reconstruction of the characteristics attributed by Pierre Rosanvallon to the phenomenon of populism is made to analyze how the democratic legitimacy degradation engendered by populism can be contained by judicialization.
\end{abstract}

Keywords: Judicialization. Legitimacy. Populism. Democracy. Political Sociology of Law.

Este artigo, dedicado à memória de Jesus Santiso Ares (1931-2020), deriva, em parte, da conferência intitulada "Democracia e instituições: uma breve abordagem teórico-conceitual", proferida em 29 de novembro de 2019, por ocasião do "I Congresso de Direito do Trabalho e Democracia", promovido pela Comissão de Direito do Trabalho e de Direito Sindical da OAB/SP. Agradeço especialmente ao Professor José Francisco Siqueira Neto pelo convite para participar do evento.

* Professor Doutor da Faculdade de Direito da Universidade de São Paulo e Professor adjunto da Faculdade de Direito da Universidade Presbiteriana Mackenzie. 
Introdução

O processo de "judiciarização" tem se firmado, historicamente, como uma característica da sociedade contemporânea. ${ }^{2}$ Diversos autores sublinham essa crescente tendência de se recorrer ao Poder Judiciário, especialmente nos sistemas democráticos. ${ }^{3}$ Segundo Martine Kaluszynski (2007), a "judiciarização", em sentido lato, poderia ser qualificada pelas seguintes características essenciais: a) a multiplicação do recurso ao Judiciário por parte dos atores sociais; b) o aumento de solicitações de intervenção judicial para o tratamento de temas fundamentais da sociedade; c) o deslocamento cada vez mais frequente do tratamento de questões afetas à arena política para a seara judiciária. Assim, como se verá a seguir, é possível constatar que a "judiciarização" acarreta uma reconfiguração das relações entre os campos "político" e "jurídico". ${ }^{4}$ É nesse sentido que

2 Cabe notar que, nesta análise, será usado o termo "judiciarização" (judiciarisation entre os autores francófonos). Essa observação se faz importante porque, no Brasil, por influência de autores anglófonos, especialmente Chester Neal Tate e Torbjörn Vallinder, prepondera o uso do vocábulo "judicialização", proveniente do inglês judicialization, para a descrição do fenômeno que será aqui examinado. Aliás, é possível afirmar que, na literatura sociológica brasileira acerca da "judicialização", obras como a de Tate e Vallinder (1995) passaram a constituir referência canônica. Maciel e Koerner (2002, p. 114), por exemplo, ao enfocarem a "judicialização", observam que "a expressão passou a compor o repertório da ciência social e do direito a partir do projeto de C. N. Tate e T. Vallinder [...]". A respeito, ver: Barboza e Kozicki (2012); Verbicaro (2008) e Veríssimo (2008). Por outro lado, no âmbito da sociologia jurídica, vale notar que a perspectiva de Campilongo $(2000,2002)$ acerca dessa questão apoia-se, especialmente, na teoria dos sistemas de Niklas Luhmann e a de Faria (2010) mobiliza Chester Neal Tate e Torbjörn Vallinder, Boaventura de Sousa Santos, Maria Manuel L. Marques, João Pedroso, Pedro L. Ferreira, Celso Fernandes Campilongo e António Casimiro Ferreira. A opção feita aqui pelo termo "judiciarização" ocorre porque este consiste na tradução literal de judiciarisation, utilizado por autores como Jacques Commaille, Jérôme Pélisse, Bruno Jobert, Thierry Delpeuch, Laurence Dumoulin, Claire de Galembert, Jacques Chevallier, Violaine Roussel e Martine Kaluszynski. Portanto, mediante o uso do termo "judiciarização" visa-se sublinhar a vinculação ao referencial teórico que balizará o presente artigo. Para uma análise, em português, da distinção entre "juridicização" e "judiciarização", ver: Villas Bôas Filho (2015).

3 A respeito, ver, especialmente: Commaille e Dumoulin (2009), Israël (2010) e Roussel (2003). Acerca da juridicização (judicialização) da política e mesmo da "megapolítica", ver, sobretudo, Hirschl (2004, 2006, 2008, 2011) e Commaille (2007b, 2010e).

4 Sobre as noções de "campo político" e de "campo jurídico", ver, especialmente: Bourdieu (1986a, 1986b, 1991, 1993, 2012). Para uma ampla análise dos conceitos de campo, capital e habitus, ver: Bourdieu (2015, 2016). A respeito da análise de Bourdieu acerca do "campo jurídico", ver, particularmente, García Villegas (2004), Guibentif (2010), Roussel (2004), Sckell (2016) e Sueur (2013). Entretanto, conforme enfatizam Commaille e Duran (2009, p. 13), a "sociologia política do direito", que será mobilizada a seguir, está "loin de renouer avec une quelconque sociologie des "champs' [...]". Ademais, Commaille $(2015,2016)$ procura demarcar a sua posição do que designa de "paradigme de la domination", por ele associado às obras de Bourdieu e de Foucault. No que tange especificamente ao autor de La noblesse d'État, Commaille (2010b, p. 178) afirma que "Pierre Bourdieu en s'attachant à souligner ce qu'il considère comme la place centrale du droit dans la perpétuation de la domination des classes dominantes, sous-estime la capacité d'acteurs sociaux, hors du champ juridique, ou éventuellement des mouvements sociaux, à mobiliser le droit pour peser sur sa définition ou sa '(re)création' dans le sens de la cause qu'ils défendent, ce que montrent les travaux actuels de sociologie". Para uma análise mitiga a avaliação de Commaille (2010b, 2015, 2016) acerca do pensamento de Bourdieu, ver Sckell (2016). No que tange à obra de Foucault, também é possível 
Jacques Commaille e Laurence Dumoulin (2009) ressaltam que a “judiciarização" seria indissociável dos novos papéis e de um novo status assumidos pela esfera jurídica em relação à política. ${ }^{5}$

Por outro lado, conforme enfatiza o historiador Pierre Rosanvallon (2020), o populismo tem se afigurado como um fenômeno contemporâneo de ampla significação, de modo a, inclusive, subverter a dinâmica do campo político no século XXI. Espraiandose por diversos países, o populismo, a despeito da carência de teorização que lhe é direcionada, demanda atenta consideração, especialmente porque, em alguns casos, coloca em risco a própria ordem democrática. ${ }^{6}$ Nesse sentido, cabe notar que, ao caracterizar-se, entre outras coisas, pela pretensão de uma relação não mediada institucionalmente com as massas, o populismo consigna a efetiva possibilidade de uma deterioração da legitimidade das instituições democráticas, tal como elas se estruturam na atualidade. ${ }^{7}$ Assim, levando em conta a importância do processo de "judiciarização" no campo político, o presente artigo, a partir de uma abordagem sociojurídica, procurará sublinhar o seu potencial de contenção da degradação populista da legitimidade democrática. ${ }^{8}$

Diante do exposto, será realizada, preliminarmente, uma breve digressão pela "sociologia política do direito" proposta pelo sociólogo francês Jacques Commaille (1). Em seguida, a "sociologia política do direito" será mobilizada como quadro teórico de referência para a análise do processo de judiciarização (2). Feito isso, será enfocada a tese de Pierre Rosanvallon acerca da complexificação da experiência democrática contemporânea decorrente do progressivo descentramento de sua legitimidade da esfera eleitoral-representativa, o que conduz à questão da emergência de novas formas de legitimação da democracia que podem ser afetadas pelo populismo, tal como esse mesmo autor o define (3). Por fim, será tratada a questão da judiciarização como um instrumento

afirmar que o entendimento de Commaille $(2015,2016)$ pode ser questionado a partir da imagem de um "direito novo", sublinhada por Fonseca (2012).

5 A respeito, ver também: Commaille (1999, 2007b, 2010c, 2010f, 2015, 2019a). Analogamente, Roussel (2003, p. 15), referindo-se especialmente à obra de Antoine Garapon, enfatiza que "Certains travaux insistent alors sur la possibilité de définir le magistrat comme nouveau représentant, ce qui le pose de facto en concurrent de l'élu, selon de nouveaux critères de légitimité".

6 Referindo-se ao populismo, Rosanvallon (2020, p. 14) afirma que "il ne se rattache à aucune œuvre d'envergure comparable, à la hauteur de la centralité qui est la sienne". A respeito, com particular ênfase no caso norte-americano, ver: Levitsky e Ziblatt (2018).

7 Para uma descrição da experiência democrática em sua configuração atual, ver, especialmente, Rosanvallon (2008). Para uma análise da polissemia do conceito de democracia, ver, por exemplo: Colliot-Thélène (2010) e Villas Bôas Filho (2013). Acerca da polissemia do conceito de populismo, ver, sobretudo, Rosanvallon (2020).

8 Vale notar que a "sociologia política do direito" é particularmente adequada ao tratamento dessa questão na medida em que, opondo-se ao que Commaille $(2015,2016)$ designa de "paradigma da dominação", procura enfatizar o direito como recurso na luta social e política. Como enfatiza Commaille (2015, p. 336), "le droit de référence intangible est reconfiguré comme ressource susceptible d'être manipulée par les acteurs sociaux en fonction des objectifs qu'ils poursuivent". 
de contenção da degradação populista do arranjo institucional que legitima a democracia (4).

\section{Elementos fundamentais da "sociologia política do direito"}

A proposta de uma "sociologia política do direito" foi introduzida por Jacques Commaille a partir de uma análise original e minuciosa da legislação de família na França, que se consubstancia no livro L'esprit sociologique des lois. Essai de sociologie politique $d u$ droit, publicado em 1994. ${ }^{9}$ No ano seguinte, o autor organizou, com o antropólogo Louis Assier-Andrieu, a publicação do livro Politiques des lois en Europe. La fliation comme modèle de comparaison, que teve por base uma extensa pesquisa comparativa realizada em diversos países. A partir de então, a proposta de uma "sociologia política do direito" começou a receber ampla acolhida no meio acadêmico francófono. Para explicitar o impacto de tal proposta, Corten (1998) observa que, no ano de 1995, em clara afinidade com a proposta de Jacques Commaille, foi criado, em Bruxelas, o Centro de Sociologia Política do Direito. ${ }^{10}$

Aludindo a autores clássicos da sociologia jurídica - especialmente Renato Treves e Jean Carbonnier -, Corten (1998) enfatiza que o interesse pela política não seria novo no âmbito da sociologia jurídica. Entretanto, segundo ele, apesar desse interesse, até o final dos anos 1990, não teria sido formulada, no contexto intelectual francês, uma definição efetiva do que poderia ser entendido por uma "sociologia política do direito". ${ }^{11}$ Aliás, Corten (1998) observa que nem mesmo a obra L'esprit sociologique des lois. Essai de sociologie politique du droit conteria uma definição explícita da disciplina e inclusive as características que fixariam sua especificidade em relação a outras abordagens que

9 Procurando delinear as balizas de sua "sociologia política do direito", Commaille (1994, p. 35) ressalta que "l'affirmation de cette conception d'une sociologie politique du droit ne serait finalement qu'une réaffirmation d'une évidence après un long détour dont les causes seraient multiples (parmi celles-ci: le refus d'un certain positivisme juridique de se 'commettre' avec le politique). Le droit est au cœur de la constitution du politique [...]. L'appréhension du droit comme fait social renvoie à une activité intellectuelle relevant des sciences sociales, plus particulièrement de la sociologie juridique, où la signification du droit est recherchée dans l'interaction du social et des expressions juridiques correspondantes, non seulement dans leurs fonctions réelles mais aussi éventuellement symboliques". Para desenvolvimentos ulteriores desse argumento, ver, especialmente, Commaille $(2013,2015,2016)$. Acerca das análises direcionadas à questão da família, ver: Commaille (1994) e Commaille, Strobel e Villac (2002).

10 Sobre a importância assumida pela "sociologia política do direito" na França, ver: Capeller (2011). Para uma apresentação introdutória, em português, da "sociologia política do direito" que, ademais, analisa, a partir dela, os fenômenos de "juridicização" e de "judiciarização", ver: Villas Bôas Filho (2015).

11 Corten (1998, p. 348) afirma, ainda, que "on ne trouvera pas non plus une définition consacrée à la sociologie politique du droit dans le Dictionnaire encyclopédique de théorie et de sociologie du droit, qui fait autorité en langue française, ni dans les manuels classiques de sociologie du droit. Un examen des principaux ouvrages consacrés à la sociologie politique aboutit à la même conclusion”. 
tomam o direito por objeto. ${ }^{12}$ Conforme se verá a seguir, em textos posteriores, Jacques Commaille procurará explicitar, em termos mais precisos, a especificidade de sua "sociologia política do direito". ${ }^{13}$

Com o propósito de ilustrar a progressiva importância adquirida pela "sociologia política do direito" no âmbito da discussão francófona, vale observar que, durante o colóquio intitulado Sociologie politique du droit. Quels acquis? Quelles perspectives? Journées en l'honneur de Jacques Commaille, expressivos autores analisaram a importância da obra desse autor, sublinhando a riqueza de perspectivas dela derivada. ${ }^{14}$ Por ocasião de tal colóquio, foi publicado o texto intitulado Une sociologie politique du droit, em que Jacques Commaille procura delinear, sinteticamente, o essencial de sua proposta. ${ }^{15}$ Para tanto, enfatiza, logo de início, que sua experiência de trabalho como sociólogo, nos anos 1970, com Jean Carbonnier ${ }^{16}$ ter-lhe-ia proporcionado a oportunidade de descobrir duas dimensões entrelaçadas do direito: a) a que diz respeito ao saber jurídico em sentido estrito; e b) a que se relaciona à inscrição do direito e sua produção no espaço político. A partir de tal experiência, o autor passou a considerar conveniente se afastar de uma visão estritamente jurídico-centrada e deslocar a questão do direito para um quadro

12 Analogamente, Caillosse (2011), aludindo aos dois volumes da revista L'Année Sociologique, publicados em 2009, sob a coordenação de Jacques Commaille e Patrice Duran, também observa a ausência de uma definição da "sociologia política do direito". De todo modo, é possível afirmar que, a despeito de não consignar uma definição mais precisa, Commaille (1994) já fixa as balizas de sua proposta teórica. Para uma excelente resenha crítica do livro L'esprit sociologique des lois. Essai de sociologie politique du droit, ver: Mosovich Pont-Lezica e Arnaud (1995).

13 Procurando definir a "sociologia política do direito", Commaille e Duran (2009, p. 13) afirmam que "loin de renouer avec une quelconque sociologie des 'champs', l'affirmation d'une sociologie politique du droit peut se définir ici comme l'étude du politique au prisme d'une sociologie du droit solidement ancrée dans une sociologie générale qu'elle entend bien féconder en retour". A respeito, ver também: Commaille (2013).

14 O colóquio, ocorrido entre 9 e 10 de setembro de 2013, na École Normale Supérieure de Cachan, contou com a participação de André-Jean Arnaud, Anne Boigeol, Anne Revillard, Anne-Marie Brocas, Aude Lejeune, Benoit Bastard, Bertrand Jouve, Catherine Marry, Cécile Vigour, Claire de Galembert, Claude Didry, Claude Martin, Elisa Chelle, Emmanuelle Bernheim, Étienne Le Roy, François Ost, Françoise Thibault, Frédéric Chauvaud, Georges Garioud, Gérôme Truc, Jacques Chevallier, Jean-François Perrin, Jean-Guy Belley, Jean-Paul Jean, Jérôme Pélisse, Laure Blevis, Laurence Dumoulin, Liora Israël, MarieClaire Lavabre, Martine Bentaboulet, Martine Kaluszynski, Mauricio García Villegas, Michel van de Kerchove, Olivier Bouin, Olivier Paye, Pascal Arnaud, Patrice Duran, Pierre Guibentif, Pierre Lascoumes, Pierre Noreau, Pierre-Paul Zalio, Romain Melot, Susan Silbey, Sylvie Thénault, Vincent-Arnaud Chappe, Violaine Roussel e Werner Gephart. Cumpre notar também que os números 1 e 2 do volume 59, de 2009, da revista L'Année Sociologique foram inteiramente dedicados à "sociologia política do direito".

15 O texto intitulado "Une sociologie politique du droit" foi originalmente veiculado pela Newsletter de La Mission de Recherche Droit et Justice - sept. 2013. Em seguida, foi traduzido para o português e publicado na Revista da Faculdade de Direito da USP. A respeito, ver: Commaille (2013).

16 Como se sabe, Jean Carbonnier é considerado responsável pela institucionalização da sociologia jurídica nas faculdades de direito francesas. Suas principais obras de sociologia jurídica são: Flexible droit. Pour une sociologie du droit sans rigueur e Sociologie juridique. Sobre a obra de Carbonnier, ver, por exemplo: Arnaud (2012), onde há, inclusive, um excelente prefácio de Jacques Commaille; Andrini e Arnaud (1995); Commaille (2007a); Verdier (2011) e Perrin (2013). 
mais amplo, anteriormente referido à "sociologia da decisão" e, em seguida, ao âmbito das políticas públicas. ${ }^{17}$

Assim, Commaille (2010a, 2013) procura inscrever a análise da regulação jurídica no âmbito dos processos mais gerais que advêm do campo político. ${ }^{18}$ Nessa perspectiva, o direito deixa de ser enfocado como fenômeno específico e passa a ser entendido como portador de um forte potencial heurístico para a compreensão do funcionamento do âmbito político do qual se torna um "revelador privilegiado". ${ }^{9}$ Commaille (2013), apoiando-se em autores como Paul Amselek, ressalta que o direito não pode ser concebido independente do exercício do poder público e de todo o contexto específico de atos e relações sociais de autoridade no qual ele se insere e que lhe fornecem seu verdadeiro relevo. A "sociologia política do direito" assume, portanto, a pretensão de promover uma interlocução estruturada com as demais ciências sociais. ${ }^{20}$

Aliás, conforme enfatiza Commaille (2013, p. 930), a partir de uma abordagem sociopolítica, o direito é "reinstituído naquilo que ele foi para as grandes figuras fundadoras da sociologia: um elemento central na construção de teorias gerais das sociedades e de suas transformações". ${ }^{21}$ Com base em tais premissas, Commaille (2013, p. 930), rejeitando a inscrição de sua perspectiva teórica no horizonte de uma "sociologia dos campos", define a "sociologia política do direito" como "o estudo do âmbito político sob o prisma de uma sociologia do direito solidamente ancorada em uma sociologia geral e de uma ciência política que essa sociologia do direito entende proficuamente retroalimentar". 22

Commaille $(2015,2016)$ sublinha que essa ampliação de perspectiva permite relacionar o estudo do direito às grandes mutações que ocorrem atualmente nas sociedades ocidentais e, simultaneamente, inscrever as análises produzidas sobre as relações entre

17 Cf. Commaille (2013) e Commaille e Duran (2009).

18 Para uma definição de “regulação jurídica”, ver, por exemplo: Arnaud (1997, 2004, 2014); Chevallier (2001, 2008) e Commaille (2019b).

19 A respeito, Commaille (2010a, p. 38) assevera que "une sociologie politique du droit est consacrée à l'analyse de l'économie des relations entre le juridique et le politique, de la place du juridique dans la construction du politique, du rôle du juridique comme révélateur du politique, ceci dans le cadre de démarches de recherche où le travail empirique est indissociable de l'investissement théorique". A respeito, ver também: Commaille (1994, 2000, 2009, 2010b, 2013, 2015, 2016, 2019a) e Commaille e Dumoulin (2009). Para comentários a esse aspecto do pensamento de Jacques Commaille, ver: García Villegas (2015) e Villas Bôas Filho (2015, 2018b, 2019d).

20 Sobre esse aspecto, ver, especialmente, Commaille (2010a, 2015, 2016).

21 Isso é particularmente evidente quando se considera a obra de Durkheim. A esse respeito, ver: Durkheim (2007 [1893]). Para uma análise que, ao contrastar Durkheim e Weber, sublinha as principais teses do primeiro acerca do direito, ver: Schluchter (2006). Sobre essa questão, ver também: Villas Bôas Filho (2017, 2019d).

22 A respeito, ver também: Commaille e Duran (2009). Por sua vez, Commaille (1991b, 1994, 2015, 2016) aponta a relação da "sociologia política do direito" com a "sociologia geral". 
direito e política em uma corrente de pesquisa internacional atualmente em curso. ${ }^{23}$ Nesse sentido, a "sociologia política do direito" procura estar atenta às metamorfoses da regulação política, identificando da seguinte maneira seus aspectos principais:

[...] substituição da noção de governança à de governo, relativização do peso do Estado-nação no contexto da globalização e da multiplicação das trocas transnacionais, transformações dos modos de intervenção do Estado marcados especialmente pela relativização dos processos de decisão top-down justificando em particular a substituição da noção de ação pública à de política pública, crise da democracia representativa, redefinição das relações entre legalidade e legitimidade correlativa à crise do modelo weberiano de dominação racional-legal, novas formas de mobilização da sociedade civil, no plano nacional mas também no supranacional (emergência de uma sociedade civil mundial) etc. (COMMAILLE, 2013, p. 930-931). ${ }^{24}$

Conforme enfatiza Commaille (2013, p. 931), essas mudanças ensejariam novas orientações de pesquisa, com forte acento interdisciplinar, para que se possa captar adequadamente a "nova economia da legalidade em relação ao âmbito político". ${ }^{25}$ Segundo Commaille (2013, 2015, 2016), a "sociologia política do direito" teria ampliado consideravelmente seus horizontes de observação e de análise, notadamente no que concerne às mudanças de estatuto assumidas pelo direito quando este passa a ser visto como um expediente suscetível de utilização em novos repertórios de ação coletiva implementados por alguns movimentos sociais ou, ainda, como um recurso instrumentalizado pela ação política. ${ }^{26}$

Commaille (2013) aponta, ainda, a afinidade da "sociologia política do direito" com perspectivas que enfocam o direito como constitutivo da realidade social e, portanto, não mais como um instrumento de regulação emanado de aparelhos institucionais destinados a intervir nessa realidade social. Assim, alinhando-se a perspectivas como as de

23 Sobre essa questão, ver também: Commaille e Jobert (1998).

24 Para uma profunda análise da governança, ver: Arnaud (2003, 2014). Para abordagens da governança que partem da obra de André-Jean Arnaud, ver: Ferreira e Pedroso (2019), Ortiz (2019) e Villas Bôas Filho (2016a, 2016c, 2018c, 2019b). Para uma ampla análise da ação pública, entendida como forma de intervenção coletiva que mobiliza múltiplos atores, tanto públicos como privados, ver, especialmente: Duran (1999).

25 Quanto a esse ponto, ver, especialmente: Commaille e Duran (2009) e Commaille (2015). Acerca da pesquisa interdisciplinar no âmbito dos estudos sociojurídicos, ver: Villas Bôas Filho (2018a, 2019a, 2019c, 2020).

26 Commaille (2015, p. 336) afirma que "le droit de référence devient effectivement instrument d'action". Para uma incontornável análise relativa aos movimentos sociais, ver: Touraine (1984). Para uma abordagem geral dessa questão, ver: Neveu (2011). Na discussão brasileira, ver: Campilongo (2012). 
Susan Silbey e de Patricia Ewick (Legal Consciousness Studies) ${ }^{27}$ à corrente internacional do cause lawyering ${ }^{28}$ e à dos activists lawyers, ${ }^{29}$ Commaille $(2013,2015)$ pretende delinear uma nova representação do direito capaz de captar a redefinição das relações dos cidadãos com as normas jurídicas e a importância particular assumida pelos profissionais do direito como atores do jogo político na medida em que dispõem da competência consistente em dominar o uso do recurso jurídico. ${ }^{30}$

Além disso, Commaille (2013) ressalta que uma "sociologia política do direito" não pode desconsiderar as transformações engendradas pelo processo de globalização no estatuto do direito e as novas funções assumidas pelo Poder Judiciário, especialmente com referência à esfera política. Aliás, Commaille (2007b, 2013, 2015) enfatiza que, no bojo desse processo, as instâncias formais de administração da justiça, inscrevendo-se em contextos supranacionais, procuram redefinir as suas funções no contexto das novas escalas territoriais que passam a abranger. ${ }^{31}$ Assim, para ilustrar as ligações por ele sustentadas entre os âmbitos jurídico e político, Commaille (2007b, 2010e) alude especialmente aos fenômenos da "juridicização" e da "judiciarização".32

2. A "juridicização" e a "judiciarização" enfocadas a partir da "sociologia política do direito"

Os processos de juridicização (juridicisation entre os autores francófonos e juridicalization ou juridification entre os anglófonos) e de judiciarização (judiciarisation entre os autores francófonos e judicialization entre os anglófonos) são objeto de especial atenção da "sociologia política do direito" de Jacques Commaille, que os associa às mudanças do "regime de legalidade" nas sociedades ocidentais contemporâneas. Conforme enfatizam Commaille e Dumoulin (2009), embora esses dois fenômenos

27 Cf. Ewick e Silbey (1998). A respeito, ver: Commaille (2006). Sobre as reverberações dos Legal Consciousness Studies na discussão francesa, ver, por exemplo: Commaille (2015, 2018); Commaille e Duran (2009); Commaille e Lacour (2018); Israël e Pélisse (2004); Pélisse (2005); Kourilsky-Augeven (2009) e Villas Bôas Filho (2019a).

28 Como referências fundamentais a esse respeito, ver: Sarat e Scheingold (2005); Commaille (2013, 2015, 2016); Commaille e Duran (2009) e Israël (2001, 2010).

29 Commaille $(2010 \mathrm{~g})$ realiza um excelente contraste das perspectivas de Stuart Scheingold, Liora Israël, Alain Supiot e de Terence C. Halliday, Lucien Karpik e Malcolm M. Feeley. A respeito, ver: Commaille (2013, 2015).

30 Referindo-se a análises precedentes, especialmente as que compõem o livro L'esprit sociologique des lois. Essai de sociologie politique du droit, Commaille (2015, p. 143) ressalta que "ces analyses illustrent de façon éloquente combien, en relation avec des contextes politiques, la maîtrise de la ressource juridique est susceptible de conférer de l'efficacité politique aux stratégies développées par les professionnels du droit". Sobre essa questão, ainda que sob outra perspectiva, ver: Bourdieu (1986b).

31 A respeito, ver, especialmente, Arnaud (2003, 2004), Faria (2002, 2010, 2011) e Faria e Kuntz (2002) e Santos (1988, 2002). A respeito, ver também: Commaille (2010d, 2015, 2019a).

32 A respeito, ver, especialmente, Commaille e Duran (2009). 
estejam frequentemente relacionados, não podem ser confundidos. ${ }^{33}$ Por conseguinte, com o intuito de explicitar as especificidades desses dois processos, serão apresentadas a seguir, em linhas gerais, as características fundamentais que o autor atribui a cada um deles, a começar pelo de juridicização.

Commaille (2010e) ressalta que a juridicização seria uma característica de nossas sociedades, observável nos mais diversos domínios. Segundo ele, a juridicização tenderia a ser acompanhada de uma judiciarização das questões sociais e políticas, sendo, neste último caso, reveladora de um deslocamento do tratamento de certas questões da arena política para a judiciária, mediante a utilização cada vez mais frequente do direito, como recurso, pelos atores sociais. Além disso, questões atinentes aos atores políticos, especialmente as relativas à corrupção, passariam a ser deslocadas para o tratamento judiciário. ${ }^{34}$ Logo, conforme Commaille (2007b), a judiciarização exprimiria, em suma, um crescimento de litígios submetidos à apreciação dos tribunais. ${ }^{35}$

Delpeuch, Dumoulin e Galembert (2014) ressaltam dois sentidos atribuíveis à noção de juridicização: a) o processo pelo qual as normas sociais partilhadas por um grupo são transformadas em regras e dispositivos jurídicos explícitos. Logo, nesse primeiro sentido, juridicização remete à "instauração de regras jurídicas destinadas a regular uma determinada relação ou atividade social", de modo a fazer com que seu respeito seja, inclusive, passível de imposição por uma instância judicial. Nesse

33 Conforme ressaltam Commaille e Dumoulin (2009, p. 70), "le phénomène de judiciarisation (judicialization) est souvent mis en relation avec un processus plus global d'expansion et de mutation de la légalité, celui de la 'juridicisation' ('juridicalization')". Segundo Roussel (2003, p. 13), "parler de juridictionnalisation ou de judiciarisation (suggérant l'extension du pouvoir des juridictions, ou seulement de celles de l'ordre judiciaire) plutôt que de juridicisation (qui fait référence aux normes juridiques plus généralement), c'est focaliser l'attention sur des mécanismes de création de norme par des juges, en particulier dans des juridictions judiciaires, lieux de construction d'un droit prétorien".

34 Em sentido análogo, Dumoulin e Robert (2010, p. 9-10) ressaltam que "ce mouvement de juridicisation $\mathrm{du}$ social et du politique - dont témoignent la prolifération te la diversification de la règle de droit, la réglementation des pratiques de financement des partis politiques, l'essor du mouvement constitutionnaliste mais aussi l'émergence de 'la question du droit [...] comme l'un des axes fondamentaux d'un débat politique rénové' - s'accompagne d'un processus parallèle de judiciarisation".

35 Commaille (2007b, p. 295) ressalta que "cette juridicisation se manifesterait par un accroissement des contentieux soumis à la justice, par les sollicitations croissantes dont elle ferait l'objet jusqu'à susciter de nouvelles formes de justice (dont les juridictions pénales internationales sont une des illustrations)". Cabe, contudo, não confundir judiciarização/judicialização com ativismo judicial. Quanto a essa questão, Barroso (2012, p. 25-26) observa que a "judicialização e o ativismo judicial são primos. Vêm, portanto, da mesma família, frequentam os mesmos lugares, mas não têm as mesmas origens. Não são gerados, a rigor, pelas mesmas causas imediatas. A judicialização, no contexto brasileiro, é um fato, uma circunstância que decorre do modelo constitucional que se adotou, e não um exercício deliberado de vontade política. A ideia de ativismo judicial está associada a uma participação mais ampla e intensa do Judiciário na concretização dos valores e fins constitucionais, com maior interferência no espaço de atuação dos outros dois Poderes". Nobre e Rodriguez (2011, p. 9 e 12), por exemplo, consideram que as expressões seriam "ideias gêmeas" e também como "contraparte necessária" ou "avesso complementar" uma da outra. Acerca do "ativismo judicial", ver, por exemplo: Barroso (2012); Engelmann (2006); Koerner (2013); Teixeira (2012) e Veríssimo (2008). 
sentido, a noção expressaria, sobretudo, o aumento da proporção das regras jurídicas na regulação da atividade social; b) o aumento progressivo dos mecanismos de imposição da regulação jurídica, referindo-se, nesse caso, também ao fenômeno da judiciarização. Por conseguinte, exprimiria, especialmente, a ampliação da "força vinculativa" das regras jurídicas, especialmente a partir da possibilidade de recurso a instâncias formais, com a decorrente de restrição da margem de autonomia deixada aos agentes no que tange à adoção de outras condutas que não aquelas prescritas juridicamente. ${ }^{36}$

Nesse particular, conforme ressaltam Delpeuch, Dumoulin e Galembert (2014), as instâncias de produção do direito frequentemente tomam as normas sociais por referência quando definem o conteúdo de certas regras jurídicas. Contudo, essa operação de produção do direito não consiste em uma mera legislação calcada em regras sociais vigentes. Ela implica, por vezes, negociações e lutas entre os agentes sociais com concepções de mundo, interesses e valores diversos. Essa abordagem considera que o direito detém um alto grau de legitimidade social e que, portanto, a juridicização de uma norma social geraria como consequência um reforço à adesão por parte de seus destinatários. Haveria, assim, uma espécie de "eficácia simbólica” própria ao direito, tal como observam Bourdieu (1986b) e García Villegas (2014). ${ }^{37}$

Aliás, Delpeuch, Dumoulin e Galembert (2014), baseando-se na obra de Pierre Bourdieu, enfatizam que o efeito de legitimação engendrado pela juridicização de uma norma a destacaria simbolicamente de interesses particulares a ela relacionados, escamoteando, assim, tudo o que nela há de arbitrário e de contingente, de modo a apresentá-la como neutra e universal. ${ }^{38}$ Remetendo às expressivas análises de Max Weber, Jürgen Habermas e Niklas Luhmann, os autores salientam, ademais, que a juridicização de um número crescente de domínios da vida social constituiria um aspecto central da dinâmica de modernização das sociedades ocidentais, relacionando-se à

36 Sobre a juridicização, ver também: Chevallier (2008), Commaille (2010e) e, a partir de outros referenciais, Teubner (1987).

37 Nesse particular, Bourdieu (1986b, p. 8) enfatiza que "en faisant accéder au statut de verdict une décision judiciaire qui doit sans doute plus aux dispositions éthiques des agents qu'aux normes pures du droit, le travail de rationalisation lui confère l'efficacité symbolique qu'exerce toute action lorsque, méconnue dans son arbitraire, elle est reconnue comme légitime. Le principe de cette efficacité réside au moins pour une part dans le fait que, sauf vigilance spéciale, l'impression de nécessité logique suggérée par la forme tend à contaminer le contenu. Le formalisme rationnel ou rationalisant du droit rationnel, que l'on tend à opposer, avec Weber, au formalisme magique des rituels et des procédures archaïques de jugement (comme le serment individuel ou collectif), participe à l'efficacité symbolique du droit le plus rationnel". Acerca do poder simbólico, ver, especialmente, Bourdieu (2001c).

38 De fato, ao delinear as bases de sua sociologia do campo jurídico, Bourdieu (1986b, p. 15) “"l'émergence du droit, écrit Jacques Ellul, se situe au point où l'impératif formulé par un des groupes composant la société globale tend à prendre une valeur universelle par sa mise en forme juridique'. Il faut en effet lier l'universalisation et la mise en forme et en formule". A respeito, ver também: Bourdieu (1986a), García Villegas (2004), Guibentif (2010), Roussel (2004) e Sckell (2016). 
emergência e à expansão do Estado moderno.$^{39}$ Considera-se, assim, que a diferenciação e a complexificação, características das sociedades modernas, ensejariam uma crescente demanda por regulamentação jurídica relacionada, de um lado, à necessidade de organizar e regular as relações de interdependência entre domínios de atividade cada vez mais numerosos e, de outro, à necessidade de limitar as externalidades negativas que eles se impõem mutuamente..$^{40}$

A pluralidade de perspectivas que se dirigem ao fenômeno de juridicização imprime ao conceito significativa polissemia. Isso implica que se estabeleça, precisamente, qual o sentido atribuído ao termo no âmbito da "sociologia política do direito". Pélisse (2007), por exemplo, sustenta que a juridicização expressaria um processo de formalização fundado sobre uma extensão do direito positivo para regulamentação das relações sociais, sobretudo fora dos tribunais, enquanto a judiciarização remeteria ao aumento do recurso à instituição judiciária e aos procedimentos formais para composição dos conflitos.

Enfatizando a recorrente confusão entre os fenômenos referidos pelos termos juridicização e judiciarização, Delpeuch, Dumoulin e Galembert (2014) também procuram traçar uma fronteira entre eles. Nesse sentido, definem a juridicização como a proliferação do direito positivo, tal como observável por meio da inflação legislativa e regulamentar, e a multiplicação das formas jurídicas de regulação das relações sociais. Trata-se, assim, do que Commaille e Dumoulin (2009) descrevem em termos de um fenômeno global de expansão e mutação da legalidade. Por outro lado, definem a judiciarização como o progressivo aumento de poder dos juízes e dos tribunais, concebendo-a, desse modo, como uma expressão do fenômeno geral de juridicização. ${ }^{41}$ É nesse sentido que Commaille

39 Como asseveram Delpeuch, Dumoulin e Galembert (2014, p. 43), "la judiciarisation d'un nombre croissant de domaines de la vie sociale constitue un aspect majeur de la dynamique de modernisation des sociétés occidentales. Elle a partie liée avec l'émergence et l'expansion de l'État'. Sobre a construção do Estado Moderno, ver, especialmente: Bourdieu (1993, 2012).

40 Referindo-se especificamente à teoria de Habermas, Delpeuch, Dumoulin e Galembert (2014) enfatizam a dinâmica paradoxal dos processos de juridicização das regulações sociais. Nesse particular, cumpre notar que o termo Verrechtlichung é utilizado por Habermas (1989b, p. 204) para ilustrar sua tese de uma colonização interna do "mundo da vida". Nesse contexto, a colonização aparece como "the juridification of communicatively structured action areas". Acerca dessa questão, Stephen K. White ressalta que há uma evolução na posição sustentada por Habermas. Segundo White (1999, p. 11), "in The Theory of Communicative Action, Habermas had certainly regarded the emergence of modern law, with its universalism and orientation to individual rights, as a significant evolutionary step in moral-practical learning. But this positive quality was seen largely as something that has kept us from recognizing the degree to which law in welfare state has in fact become a vehicle for expanding administrative power (a problem Habermas treated under the theme of 'juridification' [Verrechtlichung]). Thus, although modern law is understood in that book as deeply ambivalent, its negative side is what receives the most distinctive treatment. This one-sidedness is corrected in Facticity and Validity". A literatura especializada sobre essa questão é monumental, o que torna impossível elencá-la aqui. A respeito, ver, especialmente: Habermas (1989b). Para uma análise da "juridificação" a partir de um viés sistêmico, ver: Teubner (1987). Para uma análise da ambivalência do processo de juridicização no que tange aos povos indígenas no Brasil, ver: Villas Bôas Filho (2016b, 2017).

41 Nesse sentido, Commaille (1999) enfoca a judiciarização em termos de uma desestabilização dos tradicionais 
(2013, p. 932) ressalta que o termo judiciarização significaria, para alguns autores, "um deslocamento dos poderes Executivo e do Legislativo em direção ao judiciário para assegurar a regulação do político no lugar do político". ${ }^{42}$

Contudo, conforme observam Commaille e Dumoulin (2009), apesar de a judiciarização poder ser, em termos gerais, considerada uma forma de expressão da juridicização, a relação entre esses dois fenômenos não é linear, direta ou congruente. Ao contrário, como mostram os autores, é simplificador enfocar a judiciarização como uma expressão direta da juridicização, pois as relações que se estabelecem entre esses fenômenos são complexas e dependem de configurações históricas e nacionais, podendo, assim, assumir articulações concretas díspares. Mediante a alusão à análise de Barry Holmström acerca da experiência sueca, Commaille e Dumoulin (2009) procuram destacar concretamente o caráter não linear da relação entre juridicização e judiciarização. Como salientam os autores, no contexto sueco, a judiciarização crescente não teria decorrido da juridicização, e, sim, ao contrário, de uma espécie de compensação advinda do refluxo do papel dos juristas na vida política, ou seja, seria o progressivo escasseamento da influência dos juristas no aparelho do Estado que teria ensejado, em termos compensatórios, um crescente reforço dos tribunais como "terceiro poder". Desse modo, a judiciarização seria, em última instância, resultante de uma desjuridicização da vida política e do aparelho estatal sueco. ${ }^{43}$

A questão da judiciarização, concebida como um atributo característico das transformações experimentadas pelo âmbito político na contemporaneidade, é amplamente tratada por Jacques Commaille. ${ }^{44}$ Mobilizando uma expressiva literatura internacional sobre a questão da judiciarização, Commaille e Dumoulin (2009) identificam três ordens de questões importantes que seriam ensejadas por tal fenômeno: I - Constituiria a judiciarização uma expressão da evolução das formas de legalidade a ponto de significar uma transformação do princípio de legitimidade da dominação política? II - Representaria ela uma manifestação da relativização do monopólio do Estado moderno no tocante à produção do direito? III - Anunciaria ela uma transformação nos modos de governo ${ }^{45}$

Partindo dessas questões, Commaille e Dumoulin (2009) desenvolvem uma tentativa de definição do que entendem por judiciarização, indicando, dentre as

“territórios da justiça”. A respeito, ver também Commaille (2015).

42 Sobre essa questão, ver também: Commaille (2009, 2015, 2016). Cumpre notar que é especialmente a essa dimensão que a literatura sociológica brasileira se dirige. A respeito, ver, por exemplo: Campilongo (2000, 2002); Vianna et al. (1999); Vianna; Burgos e Salles (2007).

43 A respeito, no contexto da globalização, ver: Faria $(2002,2010)$.

44 Nesse sentido, Commaille (2015, p. 324) observa que "la judiciarisation s'inscrit alors dans un mouvement plus large: elle serait un facteur de progrès social, permettrait que soient plus et mieux défendus les droits de l'homme, les droits des plus faibles".

45 Vale mencionar que essas questões são amplamente enfocadas por Commaille (2015). 
numerosas questões que emergem da discussão internacional sobre o tema, duas que lhes parecem fundamentais. Em primeiro lugar, o papel crescente e progressivamente crucial dos tribunais na produção das políticas públicas. Em segundo lugar, o caráter central do Poder Judiciário no funcionamento das democracias. ${ }^{46}$ De acordo com os autores, essas questões seriam reveladoras de uma mudança do estatuto e do regime da legalidade em relação às transformações experimentadas pelo exercício do poder político, o que, em última instância, constitui o foco da "sociologia política do direito".

3. A questão da legitimidade democrática: breve excurso pela tese de Pierre Rosanvallon

3.1 Bases de uma análise "não escolástica” da legitimidade democrática

A proposta de Pierre Rosanvallon é particularmente interessante para a presente discussão. No bojo de sua "teoria da indeterminação democrática", ${ }^{47}$ o autor francês propõe uma sofisticada análise da legitimidade que, rejeitando a possibilidade de redução da experiência democrática apenas à sua dimensão eleitoral-representativa, enfatiza o papel institucional desempenhado por autoridades independentes, pelas Cortes Constitucionais e pela própria atividade governamental atenta aos indivíduos e às situações particulares. ${ }^{48}$ Para promover essa empreitada teórica, o autor considera insuficiente uma abordagem "procedimental" como a desenvolvida por Jürgen Habermas. ${ }^{49}$ Segundo Rosanvallon (2008), o autor de Faktizität und Geltung teria procurado ultrapassar as

46 Cf. Commaille (2007b, 2009, 2015) e Commaille e Dumoulin (2009).

47 Rosanvallon (2015b, p. 241) afirma que a sua intenção consiste em elaborar "une théorie de l'indétermination démocratique, c'est-à-dire des éléments structurant son caractère aporétique". Nesse sentido, após indicar as diferenças entre o seu projeto teórico e os de Claude Lefort e de Hans Kelsen, Rosanvallon (2015b) sustenta que o "sujeito da democracia", o seu "objeto" e os seus "procedimentos" estariam estruturalmente ligados a tensões, ambiguidades, paradoxos, aporias, assimetrias e superposições que tornariam problemáticas as tentativas de definição e de concepção a ela direcionadas. Diante disso, o autor distingue seis formas de indeterminação da democracia: 1 . as tensões estruturantes; 2 . as ambiguidades constitutivas; 3 . os efeitos da complexidade/confusão; 4. as assimetrias funcionais; 5. as variáveis de exercício; 6. a pluralidade de formas e domínios.

48 Rosanvallon (2008, p. 19-20) assevera que "la vie démocratique s'élargit donc de plus en plus au-delà de la sphère électorale-représentative. [...] Les légitimités d'impartialité, de réflexivité et de proximité [...] dérivent des caractéristiques des institutions, de leur capacité à incarner des valeurs et des principes, mais elles restent simultanément dépendantes du fait qu'elles doivent être socialement perçues comme telles. On peut de la sorte concevoir que leur déploiement puisse faire entrer les démocraties dans un nouvel âge [...] il s'agit de considérer la légitimité propre des institutions".

49 Cumpre notar que Rosanvallon (2008) cita apenas dois artigos de Habermas, publicados em francês na década de 1980, não aludindo à obra Faktizität und Geltung: Beiträge zur Diskurstheorie des Rechts und des demokratischen Rechtsstaats, de 1992, que, como se sabe, consigna a mais ampla de suas análises acerca da temática da democracia. Rosanvallon (2008) não examina, ademais, a ampla literatura dirigida ao pensamento de Habermas. Para a compreensão do teor da crítica de Rosanvallon (2008), ver, especialmente, Habermas (1989a). 
perspectivas substancialistas da democracia, mediante a proposta de consideração da "vontade geral" em termos de uma "disseminação discursiva". Contudo, em seu entendimento, Habermas remanesceria inscrito em uma visão monista da soberania popular. ${ }^{50}$ Ademais, de acordo com Rosanvallon (2008), Habermas apenas teria transferido o fundamento dessa soberania de um "corpo social", dotado de suposta consistência intrínseca, para um "espaço comunicacional difuso". ${ }^{51}$

Por outro lado, Rochlitz (2004) propõe uma profícua classificação das "teorias da democracia", em meio à qual situa a perspectiva de Pierre Rosanvallon. Conforme o autor, poder-se-ia distinguir as "teorias narrativas" das "teorias normativas" da democracia, ressaltando que as primeiras seriam características da tradição intelectual francesa e as segundas das tradições alemã e americana. Não cabe aprofundar essa discussão aqui. ${ }^{52}$ Para os propósitos deste artigo, importa notar que, para Rochlitz (2004), as "teorias narrativas", cuja característica fundamental consiste na rejeição de um "critério racional" para um "regime político justo", seriam ilustradas, especialmente, pelos pensamentos de Marcel Gauchet e de Pierre Rosanvallon. Portanto, é possível afirmar que a perspectiva de Rosanvallon, ao assumir uma figuração essencialmente histórica e refratária à enunciação de postulados normativos com pretensão de validade universal, não constituiria o que Pierre Bourdieu designa de "teoria escolástica", ou seja, como um exercício escolar no qual a "experiência mental" é o seu próprio fim. ${ }^{53}$

50 Monod (2015) também contrasta as perspectivas de Pierre Rosanvallon e de Carl Schmitt.

51 Desnecessário ressaltar que a reconstrução feita por Rosanvallon acerca do pensamento de Habermas é assaz simplista e poderia ser objeto de crítica. Para análises que, no âmbito da francofonia, enfocam a complexidade do pensamento de Habermas, ver, por exemplo: Guibentif (2010); Haber (1998); Hunyadi (1989); Le Blanc (2002); Spector (2002).

52 Procurando caracterizar essas duas perspectivas, Rochlitz (2004, p. 405-406) afirma que "les théories normatives de la société politique reconstruisent le cadre en fonction duquel les membres d'une société en évaluent les actes, les acteurs et les institutions, tout en sachant que, dans les faits, les écarts par rapport à de telles attentes de rationalité sont fréquents et normaux, comme il existe un écart entre une constitution politique et la réalité constitutionnelle avec ses retards et ses infractions. Selon ces théories, des critères normatifs sont néanmoins présupposés par tous les acteurs, dans la mesure où ils ne se satisfont pas d'admettre l'existence de traditions, de rapports de force et d'autorité, et adoptent des attitudes critiques à l'égard des autres acteurs et à l'égard des institutions existantes. Les théories narratives de la société ne supposent pas que de tels critères aient une validité générale ou universelle; elles s'appliquent plutôt à évoquer des traditions et des évolutions sans téléologie rationnelle, et elles doutent de la rationalité des acteurs. Ce sont là deux stratégies et deux paris opposés. Refuser une 'théorie normative de la démocratie' et y opposer le modèle d'une théorie narrative, d'une histoire, c'est rejeter quelque chose comme un critère rationnel du régime politique juste ou conforme aux exigences d'une société qui se veut moderne". A respeito, ver: Sabbagh (2015). Para uma boa síntese da análise de Ronsanvallon acerca da democracia francesa, a partir das obras Le sacre du citoyen (1992), Le peuple introuvable (1998) e La démocratie inachevée (2000), ver: Verdo (2002).

53 Acerca do pensamento escolástico, ver: Bourdieu $(2003,1994)$. Nesse particular, vale notar que Bourdieu (2001b) atribui esse caráter "escolástico" à teoria da ação comunicativa de Habermas e à teoria dos sistemas de Luhmann. Sobre essa questão, ver, por exemplo, Villas Bôas Filho (2018). 


\subsection{A irredutibilidade da democracia ao momento eleitoral}

Conforme Rosanvallon (2008), a ideia de que o povo seria a única fonte legítima do poder teria se expandido universalmente como a expressão da essência da democracia. Consequentemente, nas representações de senso comum, a unção popular dos governantes constituiria a principal característica de um regime democrático. Rosanvallon sustenta que, nessa perspectiva, pressupor-se-ia que a maioria equivaleria ao todo e que o momento eleitoral valeria pela duração de todo o mandato que dele recorre.

Para Rosanvallon (2008), o sufrágio universal, considerado como forma tradicional de expressão da "generalidade social", repousa sobre uma visão "agregativa" desta última, pois parte da premissa de que a massa de cidadãos-eleitores constituiria, por agregação, a "vontade geral". Por outro lado, a ideia de "serviço público", outro pilar da concepção convencional de democracia, também remeteria à ideia de uma "generalidade objetiva" consistente na suposição de que a "razão pública" ou o "interesse geral" estariam, de alguma forma, identificados às próprias estruturas do Estado republicano.

No entanto, de acordo com Rosanvallon (2008), com o fim do século XX, a complexidade social teria levado ao desmoronamento das antigas formas de apreensão da "generalidade social". Nesse contexto, a legitimação pelas urnas teria começado a se tornar progressivamente insuficiente. Observar-se-ia, assim, uma espécie de "dessacralização da função da eleição". ${ }^{4}$ Com isso, a eleição começaria a experimentar uma redução de sua função, deixando de fornecer uma espécie de legitimação a priori das políticas desenvolvidas pelo governo eleito. Assim, as eleições teriam progressivamente assumido uma função mais reduzida: a validação de um modo de designação dos governantes.

Rosanvallon (2008) também assevera que, paralelamente, o "povo" teria deixado se ser apreendido como uma espécie de "massa homogênea" para ser considerado a partir da pluralidade das identidades díspares que o constituem. Consequentemente, a noção de minoria teria ganhado progressiva importância nas sociedades contemporâneas. Entretanto, a minoria teria deixado de ser expressão da "pequena parte" do todo que, em razão de sua menor amplitude, deveria se inclinar à maioria como "grande parte", e passado a ser expressão da multiplicidade de manifestações da totalidade social. ${ }^{55}$ Aliás, a esse respeito, Rosanvallon (2014a, p. 26) afirma que a democracia não significaria apenas "poder coletivo" e "deliberação pública", e, sim "atenção a todos".

54 A respeito, Rosanvallon (2008, p. 14) é taxativo ao afirmar que "la légitimation par les urnes a d'abord reculé, du fait de la relativisation et de la désacralisation de la fonction de l'élection".

55 Rosanvallon (2008, p. 14) afirma que a minoria teria passado a ser "une des multiples expressions diffractées de la totalité sociale". 
Conforme Rosanvallon (2014a, p. 26-27), após a conquista fundamental do sufrágio universal, o desenvolvimento do ideal democrático articulou-se historicamente ao redor de duas grandes ambições. Em primeiro lugar, a de tornar a democracia mais participativa, ou seja, não restringir a intervenção dos cidadãos apenas ao momento eleitoral. Em segundo lugar, a implementação de uma democracia deliberativa, inserindo as decisões públicas em um "debate cidadão vivo". O objetivo, em ambos os casos, consistiria em passar de uma "democracia intermitente" a uma "democracia permanente" e, simultaneamente, de uma "democracia de delegação" a uma "democracia de implicação". Evidentemente que, como ressalta o autor, haveria ainda muito o que fazer nessas duas direções. Contudo, a sua posição é a de que seria necessário refundar a democracia não apenas como regime político, mas também como forma de sociedade. ${ }^{56}$

Logo, para Rosanvallon (2008), a conjugação de todos esses aspectos teria conduzido ao progressivo enfraquecimento da "esfera eleitoral-representativa" como forma de legitimação institucional do sistema democrático. Nesse sentido, o autor propõe uma análise da legitimidade democrática descentrada dessa esfera, ${ }^{57}$ pois, em seu entendimento, observar-se-ia, na atualidade, a emergência de outras maneiras de legitimação da democracia que seriam simultaneamente concorrentes e complementares à "consagração pelas urnas". Trata-se de um processo que, segundo ele, seria observável a partir do final do século XX (especialmente, a partir de 1980), período em que outras formas de expressão da "generalidade social" começariam a se delinear.

\subsection{A emergência de novas formas de legitimação}

Ao lado dessas duas formas tradicionais de expressão da "generalidade social" (de um lado, o sufrágio universal, considerado como expressão da constituição da "vontade geral", mediante a agregação da massa de cidadãos-eleitores, e, de outro, a ideia de "serviço público" como expressão da "generalidade objetiva" consistente na identificação da "razão pública" ou do "interesse geral" com as estruturas do Estado

56 $\quad$ Trata-se de uma questão importante, pois, como observa Touraine (2006, p. 107), "la démocratie [...] ne fait pas, toujours, partie du modèle européen de société". E poder-se-ia acrescentar que, de forma ainda mais evidente, também não fez parte da configuração social brasileira. A respeito, vale lembrar que Holanda (1995, p. 160) já notara que "a democracia no Brasil sempre foi um lamentável mal-entendido". Sobre o pensamento de Sérgio Buarque de Holanda relativamente às instituições brasileiras, ver: Faoro (2007, p. 267-282).

57 Como enfatiza Rosanvallon (2008, p. 19), "la vie des démocraties s'élargit donc de plus en plus au-delà de la sphère électorale-représentative". Acerca da representação política, ver, especialmente, Bourdieu (2001a). Para uma abordagem crítica das relações complexas entre democracia, república e representação, ver: Rancière (2005). Para uma excelente síntese do pensamento de Jacques Rancière, ver: Ruby (2009). Para um elucidativo contraste das perspectivas de Jacques Rancière e de Catherine Colliot-Thélène, ver: Lacroix (2015). 
republicano), Rosanvallon (2008) aponta a emergência de três outras formas, mais indiretas, de constituição da "generalidade social": a) "generalidade pela desvinculação" (généralité par le détachement); b) "generalidade de multiplicação" (généralité de démultiplication) ${ }^{58} \mathrm{c}$ ) "generalidade de atenção à particularidade" (généralité d'attention à la particularité). A cada uma dessas formas de constituição da "generalidade social" corresponderiam, respectivamente, três tipos de legitimidade: a) a "legitimidade de imparcialidade" (légitimité d'impartialité); b) a "legitimidade de reflexividade" (légitimité de réflexivité); c) a "legitimidade de proximidade" (légitimité de proximité). ${ }^{59}$

De acordo com Rosanvallon (2008), a "generalidade social", decorrente da "desvinculação" das particularidades, consistiria na equidistância vis-à-vis às diferentes partes implicadas em uma determinada questão. A qualidade da instituição envolvida nesse tipo de legitimidade seria avaliada a partir da impossibilidade de sua apropriação pessoal/personalista. Trata-se, portanto, do que o autor designa de "generalidade negativa", consistente na não tomada de partido. Conforme Rosanvallon (2008), a essa forma de "generalidade pela desvinculação" liga-se a "legitimidade de imparcialidade". ${ }^{60}$

A realização da "generalidade social” expressar-se-ia, segundo Rosanvallon (2008), por meio de um trabalho de pluralização das expressões da soberania social. A finalidade, nesse caso, seria "complexificar" a vida democrática. ${ }^{61}$ Trata-se, notadamente, de corrigir os "inadimplementos" (inaccomplissements) decorrentes da assimilação da vontade geral pela "maioria eleitoral", ou seja, da identificação do interesse da maioria com o interesse geral, com a consequente desconsideração da minoria. Nesse caso, o propósito é produzir uma "generalidade de multiplicação". ${ }^{62} \mathrm{O}$ exemplo clássico nessa

58 Em francês, "démultiplier" significa aumentar o efeito de alguma coisa mediante a multiplicação dos meios empregados. Em português, o termo "desmultiplicação" não está dicionarizado. Assim, em consonância com a tradução para o inglês, realizada por Arthur Goldhammer (generality of multiplication), optou-se aqui por traduzir a expressão "généralité de démultiplication" por "generalidade de multiplicação". Rosanvallon (2008, p. 17) define a généralité de démultiplication nos seguintes termos: "la réalisation de la généralité par le biais d'un travail de pluralisation des expressions de la souveraineté sociale. Le but est là de compliquer les sujets et les formes de la démocratie pour en réaliser les objectifs. Il s'agit notamment de corriger les inaccomplissements résultant de l'assimilation d'une majorité électorale à la volonté du corps social appréhendé dans sa globalité".

59 A respeito, ver também Rosanvallon (2015a), Lacroix (2015) e Monod (2015).

60 Segundo Rosanvallon (2008, p. 156), "la légitimité électorale repose sur une reconnaissance populaire. [...] L'impartialité est quant à elle référée à une généralité d'une autre nature: c'est une généralité négative, constituée par le fait que personne ne peut bénéficier d'un avantage ou d'un privilège. [...] L'impartialité est assimilée pour cela à une forme de détachement constitutive du désintéressement".

${ }^{61}$ Vale notar que Rosanvallon (2015b), opondo-se ao entendimento de Alexis de Tocqueville, sustenta que o progresso da democracia caracterizar-se-ia pela progressiva "complicação". Aliás, quanto a esse aspecto, Lacroix (2015, p. 161) observa que “compliquer la démocratie, c'est aussi penser la multiplication des institutions et des niveaux de représentation. Les représentants du peuple ne sont plus seulement ceux qu'il a élus. Peuvent également entrer dans cette catégorie ceux qui agissent et décident au nom du peuple - et notamment les juges constitutionnels et judiciaires".

62 Referindo-se ao que designa de "democracia eleitoral-representativa", Rosanvallon (2008, p. 195) afirma que 
seara consiste no controle de constitucionalidade, pelas Cortes Constitucionais, das decisões da maioria traduzidas no governo eleito. A essa forma de "generalidade social" liga-se a "legitimidade de reflexividade". ${ }^{63}$

Por fim, Rosanvallon (2008) faz alusão a uma "generalidade social" relativa à tomada em consideração da multiplicidade de situações e pelo reconhecimento das singularidades sociais. ${ }^{64}$ Trata-se, segundo ele, de uma forma de constituição da generalidade que implica a imersão no mundo da particularidade, cujo propósito é levar em conta os indivíduos concretos. ${ }^{65}$ Por conseguinte, estar-se-ia diante de uma "generalidade de atenção à particularidade". Para o autor, essa forma de "generalidade social" estaria ligada a uma "legitimidade de proximidade".

De acordo com Rosanvallon (2008), a emergência dessas novas formas de legitimidade conduziria à progressiva impossibilidade de redução da experiência democrática apenas à sua dimensão eleitoral-representativa. É nesse sentido que o autor alude ao que designa de "democracia pós-eleitoral". Isso significa que, nessa perspectiva, a democracia não pode ser reduzida à participação periódica em eleições para a escolha de um governante que, ungido pelas urnas e respaldado pela vontade da maioria, seria portador de uma suposta "vontade geral". ${ }^{66}$ As novas formas de legitimidade ("imparcialidade", "reflexividade" e "proximidade") seriam concorrentes e complementares à consagração pelas urnas e serviriam para o reconhecimento do que poderia ser considerado democraticamente legítimo. ${ }^{67}$

"les éléments structurants de cette vision de la démocratie se lient à trois présupposés: 1'identification du choix électoral à l'expression de la volonté générale; l'assimilation des électeurs au peuple; l'inscription durable de l'activité politique et parlementaire dans la continuité du moment électoral. La fragilité de ces énoncés n'a pas besoin d'être démontrée [...]. Le travail de réflexivité va consister à corriger l'inaccomplissement démocratique qui en découle en instaurant des mécanismes correcteurs et compensateurs de la fausseté de ces trois présupposés. Cette entreprise dessine les contours d'une généralité de démultiplication".

63 Para uma excelente análise do recurso ao Poder Judiciário como suporte da democratização, ver: Commaille (2007b).

64 Referindo-se a uma "sociedade singularista", Martuccelli (2010, p. 20), "la volonté d'un traitement différencié et personnalisé des usagers favorise la consolidation d'un rapport empathique au social, envahi par un regard compassionnel, où la souffrance des individus prend de plus en plus de place, et où, surtout, des réponses collectives et institutionnelles tendent à être 'apportées sous la forme d'une écoute' de plus en plus individualisée”. A respeito, ver também Rosanvallon (2011). Para uma sociologia do indivíduo, ver, especialmente: Martuccelli (2002) e Martuccelli e Singly (2012).

65 Rosanvallon (2008, p. 267) afirma que "la légitimité d'impartialité et la légitimité de réflexivité sont associées au développement de nouvelles institutions démocratiques. Mais les citoyens sont aussi de plus en plus sensibles au comportement même des gouvernants. Ils souhaitent être écoutés, pris en considération, faire valoir leur point de vue; ils attendent que le pouvoir soit attentif à leurs difficultés, qu'il apparaisse vraiment préoccupé par ce que vivent les gens ordinaires".

66 Vale lembrar que, para Rosanvallon (2008), a regra da maioria constitui, simultaneamente, uma "técnica de decisão" e um "princípio de legitimação".

${ }_{67}$ Assim, conforme observa Monod (2015, p. 185), “être reconnu comme 'démocratiquement légitime' ne dépend pas seulement, ou plus seulement, des urnes, de l'élection, mais de ces 'qualités' - impartialité, 
3.4 A legitimidade como "instituição invisível" da democracia e a institucionalidade das novas formas de legitimação

Rosanvallon (2008, p. 21) sustenta que a legitimidade, entendida como confiança entre os indivíduos, consistiria em uma "instituição invisível". ${ }^{68}$ Portanto, ela permitiria o estabelecimento de uma relação "sólida" entre governantes e governados. Logo, a legitimidade contribuiria para a corporificação daquilo que constitui a essência da democracia: a apropriação social (e pacífica) dos poderes, pois engendra um movimento de adesão dos cidadãos. ${ }^{69}$ Tratar-se-ia, assim, de uma "instituição invisível" e de um "indicador sensível" das expectativas políticas da sociedade e da maneira como estas são adimplidas.

Rosanvallon (2008) ressalta, ademais, que as novas formas emergentes de legitimidade democrática se articulam ao redor de alguns tipos básicos de instituição. Nessa perspectiva, a "legitimidade de imparcialidade" estaria articulada, no plano institucional, com autoridades independentes de vigilância e de regulação. A "legitimidade de reflexividade" encontraria o seu enraizamento institucional nas Cortes Constitucionais, na medida em que estas enquadram a produção legislativa a um controle reflexivo de constitucionalidade. Logo, as cortes constitucionais seriam instrumentos de redução da margem de manobra dos governos. Por sua vez, a "legitimidade de proximidade" não se atrelaria a um tipo específico de instituição. Ela remeteria a um conjunto de expectativas sociais relativas ao comportamento dos governantes. Trata-se da formação do que Rosanvallon (2008, p. 25) designa de "arte democrática de governo" (art démocratique de gouvernement). ${ }^{70}$

réflexivité - auxquelles il faut ajouter une qualité liée à 'l'art de gouverner démocratique', au comportement des gouvernements: la "proximité"'.

68 Para uma ampla análise da confiança como "instituição invisível”, ver também: Rosanvallon (2006). Complementarmente, Rosanvallon (2008, p. 21) afirma que "la légitimité est, comme la confiance entre individus, une 'institution invisible'. Elle permet à la relation des gouvernés et des gouvernants de s'établir solidement". Aliás, Rosanvallon (2015a) também assevera que a autoridade, a confiança e a legitimidade seriam três "instituições invisíveis".

69 Como já notara Aron (2019, p. 52), a democracia implica o compromisso e a adesão relativamente às regras do jogo, ou seja, à institucionalidade que figura como arcabouço jurídico-formal que regula "la concurrence pacifique pour l'exercice du pouvoir".

70 Por outro lado, Déloye (2007, p. 85) associa a "arte do governo democrático" à autodisciplina dos cidadãos. 
4. A judiciarização da política como contenção da degradação populista da legitimidade democrática

Rosanvallon (2020) ressalta que o populismo teria impactado intensamente o cenário político do século XXI. ${ }^{71}$ Diante disso, com o objetivo de esboçar uma teoria desse fenômeno expressivo, o autor se propõe a realizar uma análise composta por três etapas. Primeiramente, desenvolve uma descrição típico-ideal do que designa de "anatomia do populismo". ${ }^{72}$ Em seguida, empreende uma "história do populismo" cujo intuito consiste em integrar a caracterização típico-ideal por ele esboçada em uma tipologia geral das "formas democráticas". Por fim, procura desenvolver uma "crítica do populismo" que o correlaciona a uma teoria da democracia. Não há como recuperar em maior detalhe aqui a complexidade da análise feita por Rosanvallon (2020) acerca do populismo. Assim, o presente artigo concentrar-se-á nos elementos que, segundo o autor, exprimiriam, em caráter típico-ideal, a anatomia desse fenômeno. ${ }^{73}$

Segundo Rosanvallon (2020, p. 16), a "cultura política populista" seria constituída por cinco elementos fundamentais: a) uma concepção de povo fundada sobre a distinção "nós" e "eles"; b) uma teoria populista da democracia que prioriza a participação direta, da qual deriva a "sacralização do referendum", uma visão polarizada e "hipereleitoralista" (hyperélectoraliste) da soberania popular que rejeita os corpos intermediários e procura domesticar as instituições não eleitas (tal como as Cortes Constitucionais e as Autoridades Independentes) e uma apreensão da vontade geral como algo suscetível de expressão espontânea; c) uma concepção de representação ligada à figura de um "homem-povo" (homme-peuple) que, por suas supostas virtudes, encarnaria

71 Em diagnóstico análogo, Przeworski (2019,p. 1) enfatiza que "something is happening. 'Anti-establishment', 'anti-system', 'anti-elite', 'populist' sentiments are exploding in many mature democracies”. A respeito, com especial ênfase no caso norte-americano, ver: Levitsky e Ziblatt (2018).

72 Cabe notar que a abordagem da "anatomia do populismo" proposta por Rosanvallon (2020) abrange tanto o "populismo de direita" como o "populismo de esquerda".

73 Vale notar que a caracterização típico-ideal do populismo proposta por Rosanvallon (2020) o desenraiza de sua concreção histórica na América Latina. É bem verdade que o autor não deixa de enfocar o populismo em sua expressão latino-americana, com especial ênfase nas figuras de Jorge Eliécer Gaitán, na Colômbia, e Juan Perón, na Argentina. Contudo, Rosanvallon (2020) imprime uma conotação mais ampla ao conceito de populismo. Analogamente, Rancière (2013) afirma que o que se designa por "populismo" no debate europeu contemporâneo não é um modo de governo que encontrou em Vargas e em Péron seus arquétipos exemplares, mas certa atitude de rejeição às práticas governamentais convencionais. De todo modo, cumpre observar que Rosanvallon (2020, p. 133-144) também analisa o que é por ele designado de "laboratoire latino-américain". Para uma excelente abordagem sociológica do populismo, ver: Tarragoni (2013). Para uma definição concisa do populismo, ver: Incisa (1992). Todavia, na América Latina, ainda que assuma novas feições, o populismo também precisa ser enfocado a partir de uma perspectiva histórica, pois, nos países da região, como já notara Paz (2014, p. 14), "las épocas viejas nunca desaparecen completamente y todas las heridas, aun las más antiguas, manan sangre todavía”. Para análises clássicas de autores nacionais acerca do populismo na América Latina e no Brasil, ver, especialmente: Ianni (1991, 1994) e Weffort (2003). 
a solução para uma situação avaliada como expressiva de uma má representação popular; d) uma política e uma filosofia econômica, caracterizadas pelo "nacional-protecionismo", que instrumentalizam politicamente o campo econômico; e) um "regime de paixões e de emoções" caracterizado por "narrativas essencialmente complotistas" no plano intelectual e pelo sentimento de abandono e de invisibilidade no plano da ação. ${ }^{74}$

Tendo em consideração as características já mencionadas, observa-se que o populismo, ao investir contra os "corpos intermediários" e conceber o povo como uma massa homogênea, consigna efetivo risco de degradação de uma experiência democrática pautada pela mediação institucional e pelo pluralismo político. ${ }^{75}$ Aliás, é por esse motivo que Rosanvallon (2006) o qualifica como uma "patologia da democracia eleitoralrepresentativa". Além disso, ao exacerbar a desconfiança em face dos poderes instituídos mediante a celebração de um líder, em geral carismático, ao qual se atribui a suposta encarnação dos anseios populares, o populismo também pode engendrar uma postura antipolítica com consequências deletérias. ${ }^{76}$

Ademais, como mencionado, Rosanvallon (2008) identifica a emergência de novas formas de legitimidade ("imparcialidade", "reflexividade" e "proximidade") que, em seu entendimento, conduziriam ao progressivo incremento de complexidade da experiência democrática e à decorrente impossibilidade de sua redução à dimensão eleitoral-representativa. Essa situação faz recrudescer ainda mais o potencial destrutivo do fenômeno populista, uma vez que este, a partir da exaltação da figura do líder e de sua

74 Rosanvallon (2020 0 p. 25-75) analisa amplamente essas características ao tratar do que denomina de "anatomia" do populismo. Por sua vez, Rancière (2013) atribui três traços fundamentais ao populismo: a) um estilo de interlocução que se dirige diretamente ao povo desconsiderando seus representantes e as personalidades notáveis; b) a afirmação de que as elites dirigentes se ocupam mais de seus próprios interesses do que da coisa pública; c) uma retórica identitária refratária aos estrangeiros. Rosanvallon (2014b) referese a esses três aspectos designando-os, em seu conjunto, de "tripla simplificação do populismo". Para um exame das mutações na representação política, ver, por exemplo: Dubet e Martuccelli (1998).

75 Como observa Tarragoni (2013, p. 57), "le populisme menace la démocratie dans la mesure où cette dernière doit civiliser son peuple, maîtriser ses pulsions et l'éduquer à 'l'auto-contrainte', à résister à l'appel des 'démagogues', bref à la raison". Acerca da concepção populista de povo, ver Colliot-Thélène (2014) e, especialmente, Rosanvallon (2020). Para uma análise sociológica do qualificativo "popular", ver: Bourdieu (2001d).

76 Nessa perspectiva, vale notar que Rosanvallon (2006, p. 269-277) enfoca o populismo como uma "patologia da democracia representativa" e como uma "patologia da contrademocracia". Tarragoni (2013, p. 66) afirma que "P. Rosanvallon identifie un certain nombre de passages permettant de convertir l'exception empirique en pathologie politique. Par son apparition empirique imprévisible, le populisme est nécessairement le symptôme de quelque chose: d'une crise démocratique profonde, tenant au désenchantement, à la crise de la représentation, à la non-résolution de la question sociale. De l'imputation causale on procède immédiatement au jugement pathologisant: le populisme 'n'est-il pas la nouvelle pathologie historique de la démocratie', un cancer qui serait destiné à sortir de son idiotie empirique pour envahir, tel une métastase, la 'démocratie du XXI" siècle'?". A respeito, ver: Rosanvallon (2014b). Nesse particular, o populismo também pode ser concebido como uma espécie de forma parasitária que tem a democracia por hospedeiro. Contudo, como observa Serres (1997, p. 453), "le parasite est expansion, il court, et croît. Il envahit et il occupe". 
relação direta com as massas (lógica do referendum), engendra simplificações grosseiras e incompatíveis com a complexidade que permeia a dinâmica das sociedades democráticas. ${ }^{77}$ Por essa razão, aliás, o populismo pode promover uma degradação da democracia capaz de conduzi-la ao que Rosanvallon (2020) designa de "democratura". ${ }^{78}$

Como mencionado, as novas formas de legitimidade identificadas por Rosanvallon (2008) vincular-se-iam a alguns tipos básicos de instituição. Assim, a "legitimidade de imparcialidade" estaria articulada, no plano institucional, a autoridades independentes de vigilância e de regulação. A "legitimidade de reflexividade" encontraria o seu enraizamento institucional nas Cortes Constitucionais, na medida em que estas, ao enquadrarem a produção legislativa em um controle reflexivo de constitucionalidade, afigurar-se-iam como instrumentos de redução da margem de manobra dos governos. Por sua vez, a "legitimidade de proximidade", não se atrelando a um modelo específico de instituição, remeteria a um conjunto de expectativas sociais relativas ao comportamento dos governantes, exprimindo-se, segundo Rosanvallon (2008, p. 25), na forma de uma "arte democrática de governo".

Ora, ao promover a polarização e enaltecer a relação direta entre líder e povo sem mediação institucional, por meio da sacralização da lógica do referendum com a decorrente tentativa de domesticação das instituições não eleitas, especialmente as Cortes Constitucionais e as Autoridades Independentes, o populismo acaba por corroer o desenho institucional das democracias de modo a degenerá-las. ${ }^{79}$ É evidente que essa situação engendra um grave comprometimento da "legitimidade de reflexividade" e da "legitimidade de imparcialidade", tal como Rosanvallon (2008) as define. Contudo, é

77 Essa questão torna-se ainda mais crítica diante do que Rosanvallon (2015a, p. 11) designa de "presidencialização das democracias" (présidentialisation des démocraties).

78 Rosanvallon (2020) contrasta o que ele designa de "oligarquia eletiva", "totalitarismo" e "democratura". Quanto ao neologismo "democratura”, Rosanvallon (2020, p. 227-228) afirma que "fusionnant les mots 'démocratie' et 'dictature', il qualifie un type de régime foncièrement illibéral conservant formellement les habits d'une démocratie ('Régime politique mêlant des apparences démocratiques et un exercice autoritaire du pouvoir')". Cabe também notar que, no que tange à "democratura", tal como definida supra, Rosanvallon (2020) enfatiza, especialmente, a questão da "irreversibilidade" de um poder que, travestido de democrático, se exerce de forma autoritária. Sobre essa questão, ver também: Levitsky e Ziblatt (2018).

79 Como enfatiza Przeworski (2019, p. 88), "the populist parties are not anti-democratic in the sense that they do not advocate replacing elections by some other method of selecting government. [...]. Hence, while the populist parties are not anti-democratic, they are anti-institutional in the sense of rejecting the traditional model of representative democracy". O autor alude, ainda, ao que disse Manuel López Obrador logo após a sua derrota em 2006: "al diablo con vuestras instituciones". No mesmo sentido, Levitsky e Ziblatt (2018, p. 22) ressaltam que "populists are antiestablishment politicians - figures who, claiming to represent the voice of 'the people', wage war on what they depict as a corrupt and conspiratorial elite. Populists tend to deny the legitimacy of established parties, attacking them as undemocratic and even unpatriotic". A respeito, ver também Rosanvallon (2020) e Castells (2018). No contexto brasileiro, as reiteradas tentativas de Jair M. Bolsonaro de desqualificar o Supremo Tribunal Federal e de anular o papel das agências reguladoras, especialmente o da Anvisa, exprimem claramente essa situação. 
possível afirmar que até mesmo a "legitimidade de proximidade", que não se vincula a um tipo específico de instituição, é degradada pelo populismo. Como visto, essa forma de legitimidade remete a um conjunto de expectativas sociais relativas ao comportamento dos governantes, especialmente no que tange à consideração das "singularidades sociais". ${ }^{80}$ Ora, partindo de uma concepção homogênea de povo que, em contextos de forte polarização ideológica, reflete apenas as visões e os valores de acólitos e prosélitos fanatizados, o populismo também conduz à erosão da "legitimidade de proximidade". ${ }^{81}$

É nesse contexto que a judiciarização, tal como conceituada supra, pode servir de instrumento de contenção a esse tendencial processo de degradação da experiência democrática. ${ }^{82}$ Isso ocorre porque, conforme ressaltado, na perspectiva da "sociologia política do direito", ela pode ser entendida como um expediente suscetível de mobilização em novos repertórios de ação coletiva, implementados por movimentos sociais, ou mesmo como um recurso a ser instrumentalizado pela ação política. Ademais, como enfatiza Hirschl (2006, 2008, 2011), nas últimas décadas, observar-se-ia a transferência para os tribunais (em especial para as Cortes Constitucionais) de questões contenciosas de natureza política que ostentam inquestionável importância. $\mathrm{O}$ autor designa esse fenômeno de "judicialization of mega-politics" e de "judicialization of pure politics". 83

${ }_{80}$ Rosanvallon $(2008$, p. 267) ressalta que "la légitimité d'impartialité et la légitimité de réflexivité sont associées au développement de nouvelles institutions démocratiques. Mais les citoyens sont aussi de plus en plus sensibles au comportement même des gouvernantes. Ils souhaitent être écoutés, pris en considération, faire valoir leur point de vue; ils attendent que le pouvoir soit attentif à leurs difficultés, qu'il apparaisse vraiment préoccupé par ce que vivent les gens ordinaires".

81 O desenvolvimento de políticas públicas orientadas ao atendimento dos anseios de grupos de apoio que - partindo da ignorância, do negacionismo irracional, do fundamentalismo religioso ou do dogmatismo ideológico - pretendem impor a sua visão de mundo de modo a desqualificar o pluralismo inerente à experiência democrática acarreta, inexoravelmente, a subversão das bases de uma "legitimidade de proximidade". Tendo isso em vista, entende-se claramente a contundente frase com a qual Bobbio (2006, p. 174) encerra os seus escritos autobiográficos: "detesto i fanatici con tutta l'anima". A respeito, ver: Filippi e Lafer (2004).

82 Nesse particular, como notam Levitsky e Ziblatt (2018, p. 3), é possível observar o perecimento da democracia em virtude da degradação de suas instituições. Segundo os autores, "democracies may die at the hands not of generals but of elected leaders - presidents or prime ministers who subvert the very process that brought them to power. [...] More often, though, democracies erode slowly, in barely visible steps". Sobre a questão da "presidencialização" das democracias, ver: Rosanvallon (2015a).

83 Hirschl (2011, p. 256-257) afirma que "the judicialization of megapolitics includes a few subcategories: judicialization of electoral processes; judicial scrutiny of executive branch prerogatives in the realms of macroeconomic planning or national security matters (i.e. the demise of what is known in constitutional theory as the 'political question'doctrine); fundamental restorative justice dilemmas; judicial corroboration of regime transformation; and above all, the judicialization of formative collective identity, nation building processes and struggles over the very definition - or raison d'être - of the polity as such - arguably the most problematic type of judicialization from a constitutional theory standpoint. These emerging areas of judicialized politics expand the boundaries of national high-court involvement in the political sphere beyond the ambit of constitutional rights or federalism jurisprudence, and take the judicialization of politics 
Hirschl $(2006,2008,2011)$ sustenta que a "judicialização" da "mega" ou "pura" política abrangeria os processos e os resultados eleitorais, ${ }^{84}$ a justiça restaurativa ${ }^{85}$ e, inclusive, as discussões relativas à legitimidade dos regimes, às prerrogativas do executivo, à identidade coletiva e à própria construção nacional. Diante disso, Commaille (2007b), aludindo a uma ampla literatura internacional, sublinha a tendência, por vezes excessivamente unilateral, de ampliação do Poder Judiciário em relação aos Poderes Legislativo e Executivo, de modo a configurar o que Tate e Vallinder (1995) qualificaram de "the global expansion of judicial power". Trata-se da progressiva emergência e imposição do que poderia ser caracterizado como Juristocracy ou Courtocracy que, em diversas ocasiões, tem desempenhado um papel ativo nos processos de validação ou de invalidação de mudança de regimes políticos. ${ }^{86}$

No entanto, segundo Commaille (2007b), o cenário atual caracterizar-se-ia não apenas pelo crescente recurso aos tribunais e pela decorrente expansão do âmbito de intervenção destes. Conforme o autor, observar-se-ia na atualidade uma progressiva multiplicação da referência à justiça no espaço público. ${ }^{87}$ Partindo dessa constatação, Commaille (2007b) propõe a hipótese de que o recurso ao Poder Judiciário começaria a assumir novas formas. ${ }^{88}$ É em consonância com essa perspectiva que se sustenta aqui a

to a point that far exceeds any previous limits". No mesmo sentido, ver: Hirschl (2006, 2008).

84 Essa questão é claramente ilustrada pela reação de Donald Trump diante de sua derrota para Joe Biden. Alegando, sem provas, fraude nas eleições, Trump procura judicializar o resultado da disputa eleitoral em que foi derrotado.

85 No que tange a essa questão, Commaille (2015, p. 325) observa que "l'importance accordée à la justice 'restauratrice' dans des situations comme celles des violences d'apartheid en Afrique du Sud, de la dictature chilienne ou des dictatures dans d'autres pays d'Amérique Latine, représente une autre forme d'expression de ce phénomène de judiciarisation".

86 Há mais de uma década, Hirschl (2006, p. 732) já notava que "another emerging area of judicial involvement in mega-politics is the (in)validation of regime change". Nesse contexto, Hirschl $(2006,2008,2011)$ alude ao impeachment de diversos presidentes.

${ }_{87}$ Baseando-se nas pesquisas de vários autores, Commaille (2007b, p. 297) assevera que "au-delà de savoir s'il y a ou non un fort accroissement du recours à la justice ou des interventions de celle-ci, la référence à la justice se multiplie dans l'espace publique [...]".

88 Ao examinar a questão do crescente recurso ao direito e ao Judiciário como estratégia que passa a compor o repertório da ação pública, Commaille (2007b, p. 297) afirma que "nous avancerons l'hypothèse que ce recours à la justice prend des formes nouvelles". Analogamente, Faria (2019, p. 124) ressalta que "a judicialização da política surgiu em muitos países a partir da segunda metade do século XX. No Brasil, ganhou impulso com o surgimento da ação civil pública. Criada em 1985, ela permite que um grupo ou uma instituição possa se apresentar como representante de uma coletividade, substituindo-a processualmente. Utilizado em larga escala em decorrência da multiplicação dos movimentos sociais e entidades de defesa de direitos humanos [...], esse instrumento processual deu visibilidade a diversas reivindicações [...]. Ao colocar essas reivindicações sob a forma das técnicas e especificidades do direito, a judicialização não se limitou a multiplicar o número de litígios plurilaterais no Judiciário e a colocar em novos termos a aplicação de direitos difusos e direitos coletivos". Aliás, como ressalta Duran (1999), a judiciarização constitui uma forma de institucionalização da ação pública, entendida como um modo de intervenção coletiva em que múltiplos atores, públicos e/ou privados, estão implicados. 
possibilidade de a judiciarização da política figurar como um instrumento de contenção da corrosão populista da legitimidade das instituições democráticas. Tratar-se-ia, nesse sentido, de uma faceta do processo de "desterritorialização da justiça". ${ }^{89}$

Przeworski (2019) sustenta que, nas democracias, as eleições constituiriam o único instrumento efetivo para disciplinar os políticos. ${ }^{90}$ É possível afirmar que o recurso às instâncias judiciais cumpre um papel análogo em contextos sociais e políticos degradados pelo populismo. Isso ocorre porque a judiciarização de questões políticas submete-as ao escrutínio Poder Judiciário e, portanto, a um controle de legalidade (ou, conforme o caso, de constitucionalidade) que pode mitigar ou anular os seus efeitos e, inclusive, impor responsabilização aos implicados. ${ }^{91}$ Assim, a judiciarização, tal como definida anteriormente, pode efetivamente servir de mecanismo de contenção ao ímpeto voluntarista, ao radicalismo ideológico e à imposição unilateral e errática de pautas políticas desvinculadas do interesse público. ${ }^{92}$ É por esse motivo, aliás, que o referido fenômeno de tendencial expansão e imposição do Poder Judiciário é intensamente contestado por líderes populistas $^{93}$ que, mediante a mobilização de uma retórica "hipereleitoralista", fortemente

89 Referindo-se às mutações no "estatuto das justiça" no âmbito das "sociedades avançadas", Commaille (2007b, p. 299) afirma que "une des expressions de ces mutations serait cette déterritorialisation auquel la justice est exposée, c'est-à-dire un bouleversement de ses territoires traditionnels d'intervention".

90 Przeworski (2019, p. 6) assevera textualmente que "under democracy, the only effective device for disciplining politicians are elections".

91 A possibilidade de responder por crime comum ou de responsabilidade, especialmente onde há um arcabouço legal que estabeleça sanções aos mandatários e certa independência do Poder Judiciário, parece configurar um freio real à ação de líderes populistas com pendores autocráticos. Essa situação ilustra, aliás, a complexa relação existente entre os processos de juridicização e de judiciarização. Sobre a complexidade que permeia a relação entre juridicização e judiciarização, ver: Commaille e Dumoulin (2009), Pélisse (2007, 2009) e Villas Bôas Filho (2015). Ademais, a judiciarização submete questões políticas a uma temporalidade distinta daquela que rege o jogo político, comprometendo, por conseguinte, o efeito prático de diversas decisões populistas. Nesse particular, como observa Beriain (2008, p. 182), "no existe en las sociedades modernas un único tiempo social que marca, al estilo de las sociedades tradicionales, el pulso social [...]".

92 Não é possível desenvolver aqui um exame mais minucioso dessa questão. Como exemplo, no Brasil, ver, especialmente: a "arguição de descumprimento de preceito fundamental" proposta pelo Conselho Federal da Ordem dos Advogados do Brasil, em face do Poder Executivo Federal, por atos omissivos e comissivos praticados no contexto da crise de saúde pública ensejada pela pandemia da Covid-19 (ADPF 672), a "ação direta de inconstitucionalidade" ajuizada pela Rede Sustentabilidade contestando a Medida Provisória n. 966/2020 que "dispõe sobre a responsabilização de agentes públicos por ação e omissão em atos relacionados com a pandemia da Covid-19" (ADIn 6.421) e a "arguição de descumprimento de preceito fundamental" com pedido de medida liminar proposta pelo Partido Rede Sustentabilidade, "em face de ato do Presidente da República que desautorizou a assinatura do Ministério da Saúde no protocolo de intenção de aquisição da vacina Coronavac, desenvolvida pela farmacêutica chinesa Sinovac Biotech em parceria com o Instituto Butantan, de São Paulo" (ADPF 754). Acerca do caráter populista do Governo Federal brasileiro na gestão da pandemia da Covid-19, ver, por exemplo, Smith (2020) e Ventura e Martins (2020).

93 Rosanvallon (2020, p. 41) ilustra essa situação na França mediante a alusão a um discurso proferido por Marine Le Pen, em 26.02.2017, no qual a deputada do Front National afirma que "les magistrats sont là pour appliquer la loi, pas pour l'inventer, pas pour contrecarrer la volonté du peuple, pas pour se substituer au législateur. Une fonction publique ne doit pas autoriser son titulaire à usurper un pouvoir". No Brasil, posicionamento análogo tem sido manifestado reiteradamente, a partir de uma sintaxe mais rudimentar, pelo 
refratária às instituições, procuram reduzir o campo de intervenção dos tribunais, com especial ênfase nas Cortes Constitucionais. ${ }^{94}$

Consequentemente, não são incomuns as tentativas de mobilização popular ou de aparelhamento das instituições judiciárias como expedientes para a neutralização ou a instrumentalização da Justiça por parte dos líderes populistas. ${ }^{95}$ Levitsky e Ziblatt (2018), por exemplo, ressaltam que o processo de destruição da ordem democrática passa, entre outras coisas, pela tentativa de captura e de manipulação das Cortes de Justiça para intimidação de oponentes. ${ }^{96}$ Trata-se de uma situação complexa que ilustra o caráter ambivalente da judiciarização, pois esta também pode servir de subterfúgio aos propósitos daqueles que, "jogando o jogo", procuram subverter as suas regras..$^{97}$ É justamente diante dessa situação que os juízes, conforme o sentido que imprimam às suas decisões, podem assumir (ou não) a função de "guardiões das promessas democráticas" mediante a contenção da degradação populista da legitimidade de suas instituições. ${ }^{98}$

\section{Conclusão}

A partir da reconstrução dos traços gerais da "sociologia política do direito" proposta por Jacques Commaille, procurou-se analisar aqui o processo de judiciarização como forma de contenção da corrosão populista da legitimidade institucional das democracias contemporâneas. Assim, mediante a inscrição da judiciarização no quadro teórico proposto pelo autor, que a considera como um instrumento "revelador" das transformações experimentadas pelo exercício do poder político nas sociedades ocidentais coetâneas, procurou-se relacioná-la ao fenômeno do populismo, tal como definido por

Presidente Jair M. Bolsonaro.

94 Referindo-se à pretensão dos regimes populistas de suprimirem os corpos intermediários e as instituições independentes, Rosanvallon (2020, p. 42) sustenta que, nesse estado de coisas, poder-se-ia afirmar que "la réduction du champ d'intervention des cours constitutionnelles en ayant été la manifestation la plus éclatante". A respeito, ver também Levitsky e Ziblatt (2018).

95 Como observam Levitsky e Ziblatt (2018, p. 78), "with the courts packed and law enforcement authorities brought to heel, governments can act with impunity. Capturing the referees provides the government with more than a shield. It also offers a powerful weapon, allowing the government to selectively enforce the law, punishing opponents while protecting allies". Nessa perspectiva, como já sublinhava Commaille (1991a), a questão ética torna-se fundamental na administração da justiça.

96 Levitsky e Ziblatt (2018, p. 7-8) enfatizam que "this is how elected autocrats subvert democracy - packing and 'weaponizing' the courts and other neutral agencies, buying off the media and the private sector (or bullying them into silence), and rewriting the rules of politics to tilt the playing field against opponents. The tragic paradox of the electoral route to authoritarianism is that democracy's assassins use the very institutions of democracy - gradually, subtly, and even legally - to kill it".

97 Nessa hipótese, há que se considerar como agravante o fato de que, como bem observa Commaille (2007b, p. 314), baseando-se na tese de Galanter (1974), “les ‘joueurs' de justice ne disposent pas de ressources égales". A respeito, ver também Galanter (2013) e Israël (2013).

98 Commaille (2007b, p. 301), referindo-se a Garapon (1998), alude à possibilidade de os magistrados figurarem como "“gardiens des promesses' démocratiques". 
Pierre Rosanvallon. Tendo em vista que um desenvolvimento mais detalhado dessa temática demandaria digressões de proporções incompatíveis com as de um artigo, o propósito desta análise consistiu apenas em explicitar, sem pretensão de problematização crítica, alguns aspectos fundamentais atribuídos à judiciarização no âmbito da "sociologia política do direito" para, em seguida, enfatizar o quanto ela pode servir como instrumento de mitigação da degradação populista da legitimidade democrática.

Ao sustentar que o direito se afigura, cada vez mais, como um recurso privilegiado no jogo político, a abordagem de Jacques Commaille pode fornecer aportes importantes para a análise do modo pelo qual os diversos atores que interagem nessa seara o utilizam para a consecução de maior êxito em suas ações. Por conseguinte, várias questões se colocam no horizonte de tal perspectiva teórica. Trata-se de uma abordagem atenta, por exemplo, aos usos feitos do "recurso jurídico" pelos movimentos sociais mediante a judiciarização de suas pautas e reivindicações; ${ }^{99}$ às pesquisas que indicam o entrelaçamento do fenômeno da judiciarização com o de democratização; ${ }^{100}$ e à questão da gestão do direito como instrumento de governo para a obtenção de eficácia política para determinadas ações. ${ }^{101}$ Por esse motivo, corroborando a importância atribuída por Pierre Rosanvallon ao populismo no contexto político atual, procurou-se enfocar aqui judiciarização como instrumento de contenção da degradação da experiência democrática por ele engendrada.

Conforme indicado, o fenômeno da judiciarização é relacionado, por Jacques Commaille, ao de juridicização, porém não de maneira mecânica, o que também constitui uma virtude de sua análise. Ao insistir no fato de que a relação entre esses fenômenos não pode ser compreendida em termos de uma subsunção ou derivação recíproca automática, a "sociologia política do direito" pode contribuir para elidir simplismos que distorcem a compreensão dos fenômenos examinados. Essa observação é particularmente importante em um contexto social e político complexo como o brasileiro, no qual a existência de

99 A respeito, ver Commaille (2006, 2007b, 2013, 2015). Sobre o direito como recurso no jogo político, ver também: Commaille (2007b, 2010e, 2013, 2015, 2016).

100 Como afirma Commaille (2007b, p. 310), "la justice semble être aussi attendue de plus en plus pour répondre à ce que nous pourrions considérer comme des exigences démocratiques. Dans un reversement de perspective, il est alors possible de concevoir la justice non pas seulement comme une institution de mise en œuvre du pouvoir régalien, d'instrument de rationalisation du capitalisme [...], d'imposition d'une offre de droit et d'application du droit. Elle peut être pensée comme un espace institutionnel dans un contexte politique marqué par l'existence de systèmes polycentriques de pouvoir et autorisant, par voie de conséquence, l'expression de nouveaux modes de critique sociale, notamment par l'imposition par les acteurs sociaux, d'usages 'alternatifs' du droit, par le recours à une 'mobilisation juridique' [...] dans le cadre judiciaire. La justice devient alors le support potentiel de stratégies individuelles mais aussi d'engagements collectifs issus de la société civile". Quanto a essa questão, ver também Commaille (2009) e Commaille e Dumoulin (2009).

101 Quanto a esse ponto, ver, especialmente, Commaille (2006, 2007b). 
arranjos peculiares entre tais fenômenos não é improvável, especialmente em uma configuração política marcada pelo populismo. Assim, é possível que tais arranjos ocorram de modo variado conforme se trate de situações distintas, fazendo com que a judiciarização possa decorrer, em alguns casos, da juridicização e, em outros, como compensação da desjuridicização. ${ }^{102}$

Em face do exposto, procurou-se sublinhar que a judiciarização pode proporcionar a contenção da degradação populista da legitimidade democrática. Para tanto, com o propósito de evidenciar a incompatibilidade entre democracia e populismo, foi enfocada a tese de Rosanvallon (2008) acerca da emergência de novas formas de legitimidade ("imparcialidade", "proximidade" e "reflexividade") que, em seu entendimento, conduziria ao progressivo incremento de complexidade da experiência democrática e à decorrente impossibilidade de sua redução à dimensão eleitoralrepresentativa. Assim, buscou-se enfatizar que o populismo, ao promover a sacralização da lógica do referendum com a consequente tentativa de domesticação das instituições não eleitas, acaba por corroer a legitimidade das democracias de modo a degenerá-las. Nesse contexto, foi ressaltado que o processo de judiciarização, a despeito de sua ambivalência, pode figurar como um instrumento de contenção dos efeitos deletérios produzidos pelo populismo.

São Paulo, agosto de 2020.

\section{Referências}

ANDRINI, Simona; ARNAUD, André-Jean. Jean Carbonnier, Renato Treves et la sociologie du droit: archéologie d'une discipline: entretiens et pièces. Paris: LGDJ, 1995.

ARNAUD, André-Jean. Critique de la raison juridique: 1. Où va la sociologie du droit? Paris: LGDJ, 1981.

ARNAUD, André-Jean. La valeur heuristique de la distinction interne/externe comme grande dichotomie pour la connaissance du droit: éléments d'une démystification. Droit et Société, Paris, n. 2, p. 139-141, 1986.

ARNAUD, André-Jean. De la régulation par le droit à l'heure de la globalisation. Quelques observations critiques. Droit et Société, Paris, n. 35, p. 11-35, 1997.

ARNAUD, André-Jean. Critique de la raison juridique. Paris: LGDJ, 2003. v. 2: Gouvernants sans frontières: entre mondialisation et post-mondialisation.

102 Sobre a relação complexa entre juridicização e judiciarização, ver: Commaille e Dumoulin (2009) e Villas Bôas Filho (2015). 
ARNAUD, André-Jean. Entre modernité et mondialisation: leçons d'histoire de la philosophie du droit et de l'État. 2. ed. Paris: LGDJ, 2004.

ARNAUD, André-Jean. Jean Carbonnier: un juriste dans la cité. Paris: LGDJ, 2012.

ARNAUD, André-Jean. La gouvernance: un outil de participation. Paris: LGDJ, 2014.

ARON, Raymond. Introduction à la philosophie politique: démocratie et révolution. Paris: Le livre de Poche, 2019.

BARBOZA, Estefânia Maria de Queiroz; KOZICKI, Katya. Judicialização da política e controle judicial de políticas públicas. Revista Direito GV, São Paulo, v. 8, n. 1, p. 59-86, jan./jun. 2012.

BARROSO, Luís Roberto. Judicialização, ativismo judicial e legitimidade democrática. [Syn] Thesis, Rio de Janeiro, v. 5, n. 1, p. 23-32, 2012.

BERIAIN, Josetxo. Aceleración y tiranía del presente: la metamorfosis en las estructuras temporales de la modernidad. Rubi (Barcelona): Anthropos Editorial; México: Universidad Autónoma Metropolitana - Iztapalapa, 2008.

BOBBIO, Norberto. De senectute e altri scritti autobiografici. Torino: Einaudi, 2006.

BOURDIEU, Pierre. Habitus, code et codification. Actes de la Recherche en Sciences Sociales, Paris, v. 64, p. 40-44, Sept. 1986a.

BOURDIEU, Pierre. La force du droit. Éléments pour une sociologie du champ juridique. Actes de la Recherche en Sciences Sociales, Paris, v. 64, p. 3-19, Sept. 1986b.

BOURDIEU, Pierre. Les juristes, gardiens de l'hypocrisie collective. In: CHAZEL, François; COMMAILLE, Jacques (dir.). Normes juridiques et régulation sociale. Paris: LGDJ, 1991. p. 9599. (Collection Droit et Société).

BOURDIEU, Pierre. Esprits d'État: genèse et structure du champ bureaucratique. Actes de la Recherche en Sciences Sociales, Paris, v. 96-97, p. 49-62, mars. 1993.

BOURDIEU, Pierre. Raisons pratiques: sur la théorie de l'action. Paris: Éditions du Seuil, 1994.

BOURDIEU, Pierre. La représentation politique. In: BOURDIEU, Pierre. Langage et pouvoir symbolique. Paris: Éditions Fayard, 2001a. p. 213-258.

BOURDIEU, Pierre. Science de la science et réflexivité: cours du Collège de France 2000-2001. Paris: Éditions Raisons d'Agir, 2001b.

BOURDIEU, Pierre. Sur le pouvoir symbolique. In: BOURDIEU, Pierre. Langage et pouvoir symbolique. Paris: Éditions Fayard, 2001c. p. 201-211.

BOURDIEU, Pierre. Vous avez dit 'populaire'? In: BOURDIEU, Pierre. Langage et pouvoir symbolique. Paris: Éditions Fayard, 2001d. p. 132-151.

BOURDIEU, Pierre. Méditations pascaliennes. Paris: Éditions du Seuil, 2003. 
BOURDIEU, Pierre. Sur l'État: cours au Collège de France 1989-1992. Paris: Raisons d'Agir/ Éditions Seuil, 2012.

BOURDIEU, Pierre. Sociologie générale: cours au Collège de France (1981-1983). Paris: Raisons d'Agir/Éditions du Seuil, 2015. v. 1.

BOURDIEU, Pierre. Sociologie générale: cours au Collège de France (1983-1986). Paris: Raisons d'Agir/Éditions du Seuil, 2016. v. 2.

CAILlOSSE, Jacques. La sociologie politique du droit, le droit et les juristes. Droit et Société, Paris, n. 77, p. 187-206, 2011.

CAMPILONGO, Celso Fernandes. O direito na sociedade complexa. São Paulo: Max Limonad, 2000.

CAMPILONGO, Celso Fernandes. Política, sistema jurídico e decisão judicial. São Paulo: Max Limonad, 2002.

CAMPILONGO, Celso Fernandes. Interpretação do direito e movimentos sociais. Rio de Janeiro: Elsevier, 2012.

CAPELLER, Wanda. Relire Giddens: entre sociologie et politique. Paris: LGDJ, 2011.

CASTELLS, Manuel. Ruptura: a crise da democracia liberal. Tradução Joana Angélica d'Avila Melo. Rio de Janeiro: Zahar, 2018.

CHEVALLIER, Jacques. L'État de droit. Paris: Montchrestien, 1992.

CHEVALLIER, Jacques. La régulation juridique en question. Droit et Société, Paris, n. 49, p. 827846, 2001.

CHEVALLIER, Jacques. L'État post-moderne. 3. ed. Paris: LGDJ, 2008.

COLliOT-THÉLÈNE. Catherine. La démocratie sans «démos». Paris: Presses Universitaires de France, 2010.

COLLIOT-THÉLÈNE, Catherine. Quel est le peuple du populisme? In: COLLIOT-THÉLÈNE, Catherine; GUÉNARD, Florent (dir.). Peuples et populismes. Paris: Presses Universitaires de France, 2014. p. 5-25. (Coll. La vie des idées.).

COMMAILLE, Jacques. Éthique et droit dans l'exercice de la fonction de justice. Sociétés Contemporaines, Paris, v. 7, n. 3, p. 87-101, sept. 1991a.

COMMAILLE, Jacques. Normes juridiques et régulation sociale. Retour à la sociologie générale. In: COMMAILLE, Jacques; CHAZEL, François (dir.). Normes juridiques et régulation sociale. Paris: LGDJ, 1991b. p. 13-22.

COMMAILLE, Jacques. L'esprit sociologique des lois: essai de sociologie politique du droit. Paris: Presses Universitaires de France, 1994. 
COMMAILlE, Jacques. La déstabilisation des territoires de justice. Droit et Société, Paris, n. 42/43, p. 239-264, 1999.

COMMAILLE, Jacques. Transformations du droit et de l'action publique. Économie Rurale, Paris, n. 260 , p. $20-25,2000$.

COMMAILLE, Jacques. Nouvelle économie de la légalité, nouvelles formes de justice, nouveau régime de connaissance: l'anthropologie du droit avait-elle raison? In: EBERHARD, Christoph; VERNICOS, Geneviève (ed.). La quête anthropologique du droit: autour de la démarche d'Étienne Le Roy. Paris: Karthala, 2006. p. 351-368.

COMMAILLE, Jacques. La construction d'une sociologie spécialisée: le savoir sociologique et la sociologie juridique de Jean Carbonnier. L'Année Sociologique, Paris, v. 57, n. 2, p. 275-299, 2007a.

COMMAILLE, Jacques. La justice entre détraditionnalisation, néolibéralisation et démocratisation: vers une théorie de sociologie politique de la justice. In: COMMAILLE, Jacques; KALUSZYNSKI, Martine (dir.). La fonction politique de la justice. Paris: La Découverte, 2007b. p. 295-321.

COMMAILLE, Jacques. O modelo de Janus da regulação jurídica: o caráter revelador das transformações do estatuto político da justiça. Revista Crítica de Ciências Sociais, Coimbra, n. 87, p. 95-119, 2009.

COMMAILlE, Jacques. De la "sociologie juridique" à une sociologie politique du droit. In: COMMAILlE, Jacques; DUMOULIN, Laurence; ROBERT, Cécile (dir.). La juridicisation du politique. Paris: LGDJ, 2010a. p. 29-51.

COMMAILLE, Jacques. Droit et sociologie: des rapports au risque de l'histoire. In: TERRÉ, François (dir.). Regards sur le droit. Paris: Dalloz, 2010b, p. 173-181.

COMMAILLE, Jacques. ¿Es la justicia la nueva "razón” política universal? Pensamiento Jurídico, Bogotá, n. 27, p. 69-84, ene./abr. 2010c.

COMMAILLE, Jacques. Justice. In: ARNAUD, André-Jean (dir.). Dictionnaire de la globalisation. Paris: LGDJ, 2010d. p. 302-310.

COMMAILLE, Jacques. La juridicisation du politique: entre réalité et connaissance de la réalité: en guise de conclusion. In: COMMAILLE, Jacques; DUMOULIN, Laurence; ROBERT, Cécile (dir.). La juridicisation du politique. Paris: LGDJ, 2010e. p. 199-210.

COMMAILlE, Jacques. Le droit dans le politique. Actualité d'un projet (Postface). In: COMMAILlE, Jacques; DUMOULIN, Laurence; ROBERT, Cécile (dir.). La juridicisation du politique. Paris: LGDJ, 2010f. p. 211-226.

COMMAILlE, Jacques. Les vertus politiques du droit: mythes et réalités. Droit et Société, Paris, n. 76 , p. $695-713,2010 \mathrm{~g}$.

COMMAILLE, Jacques. Uma sociologia política do direito. Revista da Faculdade de Direito da Universidade de São Paulo, São Paulo, v. 108, p. 929-933, jan./dez. 2013. 
COMMAILLE, Jacques. À quoi nous sert le droit? Paris: Gallimard, 2015.

COMMAILLE, Jacques. À quoi nous sert le droit pour comprendre sociologiquement les incertitudes des sociétés contemporaines? SociologieS, Toulose, p. 1-12, 2016. Disponível em: http://sociologies.revues.org/5278. Acesso em: 7 mar. 2016.

COMMAILLE, Jacques. Les Legal Consciousness Studies selon Susan Silbey: une dissonance entre données empiriques et ressources théoriques? Droit et Société, Paris, n. 100, p. 657-664, 2018.

COMMAILLE, Jacques. Métamorphoses de la justice et nouveaux régimes de régulation sociale et politique des sociétés contemporaines. In: ALBE, Virginie; COMMAILLE, Jacques; LE BOT, Florent (dir.). L'échelle des régulations politiques, XVIIIe-XXIe siècles: 1'histoire et les sciences sociales aux prises avec les normes, les acteurs et les institutions. Villeneuve d'Ascq: Presses Universitaires de Septentrion, 2019a. p. 223-245.

COMMAILLE, Jacques. Peut-on encore parler de régulation. In: ALBE, Virginie; COMMAILLE, Jacques; LE BOT, Florent (dir.). L'échelle des régulations politiques, XVIIIe-XXIe siècles: 1'histoire et les sciences sociales aux prises avec les normes, les acteurs et les institutions. Villeneuve d'Ascq: Presses Universitaires de Septentrion, 2019b. p. 397-405.

COMMAILLE, Jacques; DUMOULIN, Laurence. Heurs et malheurs de la légitimité dans les sociétés contemporaines: une sociologie politique de la "judiciarisation". L'Année Sociologique, Paris, v. 59, n. 1, p. 63-107, 2009.

COMMAILlE, Jacques; DURAN, Patrice. Pour une sociologie politique du droit: présentation. L’Année Sociologique, Paris, v. 59, n. 1, p. 11-28, 2009.

COMMAILLE, Jacques; JOBERT, Bruno. Introduction: la régulation politique: l'émergence d'un nouveau régime de connaissance? In: COMMAILLE, Jacques; JOBERT, Bruno (dir.). Les métamorphoses de la régulation politique. Paris: LGDJ, 1998. p. 11-32.

COMMAILLE, Jacques; LACOUR, Stéphanie. Les Legal Consciousness Studies comme laboratoire d'un régime renouvelé de connaissance sur le droit. Présentation du dossier. Droit et Société, Paris, n. 100 , p. $547-558,2018$.

COMMAILLE, Jacques; PERRIN, Jean-François. Le modèle de Janus de la sociologie du droit. Droit et Société, Paris, n. 1, p. 95-110, 1985.

COMMAILLE, Jacques; STROBEL, Pierre; VILLAC, Michel. La politique de la famille. Paris: La Découverte, 2002.

CORTEN, Olivier. Éléments de définition pour une sociologie politique du droit. Droit et Société, Paris, n. 39, p. 347-370, 1998.

DÉLOYE, Yves. Sociologie historique du politique. Paris: La Découverte, 2007.

DELPEUCH, Thierry; DUMOULIN, Laurence; GALEMBERT, Claire de. Sociologie du droit et de la justice. Paris: Armand Colin, 2014. 
DUBET, François; MARTUCCELLI, Danilo. Dans quelle société vivons-nous? Paris: Éditions du Seuil, 1998.

DUMOULIN, Laurence; ROBERT, Cécile. Autour des enjeux d'une ouverture des sciences $\mathrm{du}$ politique au droit: quelques réflexions en guise d'introduction. In: COMMAILLE, Jacques; DUMOULIN, Laurence; ROBERT, Cécile (dir.). La juridicisation du politique. Paris: LGDJ, 2010. p. 9-26.

DURAN, Patrice. Penser l'action publique. Paris: LGDJ, 1999.

DURKHEIM, Émile. De la division du travail social. 7. ed. Paris: Presses Universitaires de France, 2007. [1893].

ENGELMANN, Fabiano. Internacionalização e ativismo judicial: as causas coletivas. Lua Nova, São Paulo, v. 69, p. 123-146, 2006.

EWICK, Patricia; SILBEY, Susan. The common place of law: stories from everyday life. Chicago: The University of Chicago Press, 1998.

FAORO, Raymundo. Sérgio Buarque de Holanda: analista das instituições brasileiras. In: FAORO, Raymundo. A república inacabada. São Paulo: Globo, 2007. p. 267-282.

FARIA, José Eduardo. O direito na economia globalizada. São Paulo: Malheiros, 2002.

FARIA, José Eduardo. Sociologia jurídica: direito e conjuntura. São Paulo: Saraiva, 2010.

FARIA, José Eduardo. O Estado e o direito depois da crise. São Paulo: Saraiva, 2011.

FARIA, José Eduardo. Corrupção, justiça e moralidade pública. São Paulo: Perspectiva, 2019.

FARIA, José Eduardo; KUNTZ, Rolf Nelson. Qual o futuro dos direitos? Estado, mercado e justiça na reestruturação capitalista. São Paulo: Max Limonad, 2002.

FERREIRA, António Casimiro; PEDROSO, João. Pour une «sociologie du droit renouvelée»: de la crique de la raison juridique à la gouvernance. In: CAPELLER, Wanda; COMMAILLE, Jacques; ORTIZ, Laure (dir.). Repenser le droit: hommage à André-Jean Arnaud. Paris: LGDJ, 2019. p. 193204.

FILIPPI, Alberto; LAFER, Celso. A presença de Bobbio: América Espanhola, Brasil, Península Ibérica. São Paulo: Unesp, 2004.

FONSECA, Márcio Alves da. Michel Foucault e o direito. 2. ed. São Paulo: Saraiva, 2012.

GALANTER, Marc. Why the "haves" come out ahead: speculations on the limits of legal change. Law \& Society Review, Hoboken, v. 9, n. 1, p. 95-160, 1974.

GALANTER, Marc. Pourquoi les mêmes gardent l'avantage? Introduction à la traduction française. Droit et Société, Paris, n. 85, p. 559-574, 2013. 
GARAPON, Antoine. O guardador de promessas: justiça e democracia. Tradução Francisco Aragão. Lisboa: Instituto Piaget, 1998.

GARCÍA VILlEGAS, Mauricio. On Pierre Bourdieu's legal thought. Droit et Société, Paris, n. 56/57, p. 57-70, 2004.

GARCÍA VILLEGAS, Mauricio. La eficacia simbólica del derecho: sociología política del campo jurídico en América Latina. 2. ed. Bogotá: IDEPRI: Debate, 2014.

GARCÍA VILLEGAS, Mauricio. Les pouvoirs du droit: analyse comparée d'études sociopolitiques du droit. Paris: LGDJ, 2015.

GUIBENTIF, Pierre. Foucault, Luhmann, Habermas, Bourdieu. Une génération repense le droit. Paris: LGDJ, 2010.

HABER, Stéphane. Habermas et la sociologie. Paris: Presses Universitaires de France, 1998.

HABERMAS, Jürgen. La souveraineté populaire comme procédure: un concept normatif d'espace public. Lignes, Paris, n. 7, p. 29-58, 1989a.

HABERMAS, Jürgen. Law as medium and law as institution. In: TEUBNER, Gunther (org.). Dilemmas of law in the welfare state. Berlin: Walter de Gruyther/European University Institute, 1989b. p. 203-220.

HIRSCHL, Ran. Towards juristocracy: the origins and consequences of the new constitutionalism. Cambridge, MA: Harvard University Press, 2004.

HIRSCHL, Ran. The new constitutionalism and the judicialization of pure politics worldwide. Fordham Law Review, New York, v. 75, n. 2, p. 721-753, 2006.

HIRSCHL, Ran. The judicialization of mega-politics and the rise of political courts. Annual Review of Political Science, Vanves, v. 11, p. 93-118, 2008.

HIRSCHL, Ran. The judicialization of politics. In: GOODIN, Robert E. (ed.). The Oxford handbook of political science. Oxford: Oxford University Press, 2011. p. 253-274.

HOLANDA, Sérgio Buarque. Raizes do Brasil. 26. ed. São Paulo: Companhia das Letras, 1995.

HUNYADI, Mark. La souveraineté de la procédure: a propos de la pensée politique de Jürgen Habermas. Lignes, Paris, n. 7, p. 11-27, 1989.

IANNI, Octavio. A formação do Estado populista na América Latina. 2. ed. Rio de Janeiro: Civilização Brasileira, 1991.

IANNI, Octavio. O colapso do populismo no Brasil. 5. ed. Rio de Janeiro: Civilização Brasileira, 1994.

INCISA, Ludovico. Populismo. In: BOBBIO, Norberto; MATTEUCCI, Nicola; PASQUINO, Gianfranco (org.). Dicionário de política. Tradução Carmen C. Varriale et al. 4. ed. Brasília: Editora da Universidade de Brasília, 1992. v. 2, p. 980-986. 
ISRAËL, Liora. Usages militants du droit dans l'arène judiciaire: le cause lawyering. Droit et Société, Paris, n. 49, p. 793-824, 2001.

ISRAËL, Liora. L'arme du droit. Inflexions, Paris, n. 15, p. 101-108, 2010.

ISRAËL, Liora. Les joueurs répétés ont-ils plus de chance de gagner? Débats sur le sens de la justice: présentation du dossier. Droit et Société, Paris, n. 85, p. 543-557, 2013.

ISRAËL, Liora; PÉLISSE, Jérôme. Quelques éléments sur les conditions d'une ‘importation' (note liminaire à la traduction du texte de S. Silbey et P. Ewick). Terrains et Travaux, Saclay, n. 6, p. 101$111,2004$.

KALUSZYNSKI, Martine. La fonction politique de la justice: regards historiques: du souci d'historicité à la pertinence de l'historicisation. In: COMMAILLE, Jacques; KALUSZYNSKI, Martine (dir.). La fonction politique de la justice. Paris: La Découverte, 2007. p. 9-23.

KOERNER, Andrei. Ativismo judicial? Jurisprudência constitucional e política do STF pós-88. Novos Estudos CEBRAP, São Paulo, v. 96, p. 69-85, jul. 2013.

KOURILSKY-AUGEVEN, Chantal. Socialisation, socialisation juridique et conscience du droit. In: RUDE-ANTOINE, Edwige; CHRÉTIEN-VERNICOS, Geneviève (coord.). Anthropologies et droits: état des savoirs et orientations contemporaines. Paris: Dalloz, 2009. p. 245-269.

LACROIX, Justine. Luttes de droits et complication démocratique: la démocratie intégrale selon Pierre Rosanvallon. In: AL-MATARY, Sarah; GUÉNARD, Florent (dir.). La démocratie à l'œuvre: autour de Pierre Bourdieu. Paris: Éditions du Seuil, 2015. p. 145-164.

LE BLANC, Guillaume. Le nouvel esprit de la démocratie. Lumières, Bordeaux, n. 19, p. 195-205, 2012. (Dossier Les Lumières de Jürgen Habermas).

LEVITSKY, Steven; ZIBLATT, Daniel. How democracies die. New York: Crown Publishing, 2018. MACIEL, Débora Alves; KOERNER, Andrei. Sentidos da judicalização da política: duas análises. Lua Nova, São Paulo, n. 57, p. 113-133, 2002.

MARTUCCELLI, Danilo. Grammaires de l'individu. Paris: Gallimard, 2002.

MARTUCCELLI, Danilo. La société singulariste. Paris: Armand Colin, 2010.

MARTUCCELLI, Danilo; SINGLY, François de. Les sociologies de l'individu. Paris: Armand Colin, 2012.

MONOD, Jean-Claude. Les légitimités démocratiques en tension. In: AL-MATARY, Sarah; GUÉNARD, Florent (dir.). La démocratie à l'œuvre: autour de Pierre Bourdieu. Paris: Éditions du Seuil, 2015. p. 181-195.

MOSOVICH PONT-LEZICA, Diana; ARNAUD, André-Jean. Quand l'esprit politique vient aux sociologues du droit. Droit et Société, Paris, n. 30-31, p. 473-483, 1995.

NEVEU, Érik. Sociologie des mouvements sociaux. 5. éd. Paris: La Découverte, 2011. 
NOBRE, Marcos; RODRIGUEZ, José Rodrigo. "Judialização da política": déficits normativos e bloqueios normativistas. Novos Estudos CEBRAP, São Paulo, v. 91, p. 5-20, 2011.

ORTIZ, Laure. La gouvernance, l'outil d'une pensée juridique projective. In: CAPELLER, Wanda; COMMAILLE, Jacques; ORTIZ, Laure (dir.). Repenser le droit: hommage à André-Jean Arnaud. Paris: LGDJ, 2019. p. 223-232.

PAZ, Octavio. El labirinto de la soledad. México: Fondo de Cultura Económica, 2004.

PÉLISSE, Jérôme. A-t-on conscience du droit? Autour des Legal Consciousness Studies. Genèses, Paris, n. 59, p. 114-130, 2005.

PÉLISSE, Jérôme. Les usages syndicaux du droit et de la justice. In: COMMAILLE, Jacques; KALUSZYNSKI, Martine (dir.). La fonction politique de la justice. Paris: La Découverte, 2007. p. $165-189$.

PÉLISSE, Jérôme. Judiciarisation ou juridicisation? Usages et réappropriations du droit dans les conflits du travail. Politix, v. 22, n. 86, p. 73-96, 2009.

PERRIN, Jean-François. Jean Carbonnier: la référence comme héritage. Droit et Société, Paris, n. 84, p. 477-486, 2013.

PRZEWORSKI, Adam. Crises of democracy. Cambridge: Cambridge University Press, 2019.

RANCIÈRE, Jacques. La haine de la démocratie. Paris: La Fabrique, 2005.

RANCIÈRE, Jacques. L'introuvable populisme. In: BADIOU, Alain et al. Qu'est-ce qu'un peuple? Paris: La Fabrique, 2013. p. 137-143.

ROCHLITZ, Rainer. Théories narratives et théories normatives de la démocratie. Les Études Philosophiques, Paris, n. 70, p. 404-418, 2004.

ROSANVALLON, Pierre. La contre-démocratie: la politique à l'âge de la défiance. Paris: Éditions du Seuil, 2006.

ROSANVALLON, Pierre. La légitimité démocratique: impartialité, réflexivité, proximité. Paris: Éditions du Seuil, 2008.

ROSANVALLON, Pierre. La société des égaux. Paris: Éditions du Seuil, 2011.

ROSANVAlLON, Pierre. Le parlement des invisibles. Paris: Les Éditions du Seuil et Raconter la vie, 2014a.

ROSANVALLON, Pierre. Penser le populisme. In: COLLIOT-THÉLÈNE, Catherine; GUÉNARD, Florent (dir.). Peuples et populismes. Paris: Presses Universitaires de France, 2014b. p. 27-42. (Coll. La vie des idées).

ROSANVALLON, Pierre. Le bon gouvernement. Paris: Éditions du Seuil, 2015a. 
ROSANVALLON, Pierre. Postface: bref retour sur mon travail. In: AL-MATARY, Sarah; GUÉNARD, Florent (dir.). La démocratie à l'œuvre: autour de Pierre Bourdieu. Paris: Éditions du Seuil, 2015b. p. 229-250.

ROSANVALLON, Pierre. Le siècle du populisme: histoire, théorie, critique. Paris: Éditions du Seuil, 2020.

ROUSSEL, Violaine. La judiciarisation du politique, réalités et faux semblants. Mouvements, Paris, v. 4, n. 29 , p. 13-18, sept./oct. 2003.

ROUSSEL, Violaine. Le droit et ses formes. Éléments de discussion de la sociologie du droit de Pierre Bourdieu. Droit et Société, Paris, n. 56-57, p. 41-55, 2004.

RUBY, Christian. L'interruption: Jacques Rancière et la politique. Paris: La Fabrique, 2009.

SABBAGH, Daniel. Pierre Rosanvallon, théoricien de l'égalité démocratique. In: AL-MATARY, Sarah; GUÉNARD, Florent (dir.). La démocratie à l'œuvre: autour de Pierre Bourdieu. Paris: Éditions du Seuil, 2015. p. 165-179.

SANTOS, Boaventura de Sousa. Droit: une carte de la lecture déformée: pour une conception postmoderne du droit. Droit et Société, Paris, n. 10, p. 363-390, 1988.

SANTOS, Boaventura de Sousa. Para um novo senso comum: a ciência, o direito e a política na transição paradigmática. 4. ed. São Paulo: Cortez, 2002.

SARAT, Austin; SCHEINGOLD, Stuart A. (dir.). The worlds cause lawyers make: structure and agency in legal practice. Stanford, CA: Stanford University Press, 2005.

SCKELL, Soraya Nour. Os juristas e o direito em Bourdieu: a conflituosa construção histórica da racionalidade jurídica. Tempo Social, São Paulo, v. 28, n. 1, p. 157-178, 2016.

SCHLUCHTER, Wolfgang. La sociologie du droit comme théorie empirique de la validité. In: HEURTIN, Jean-Philippe; MOLFESSIS, Nicolas (dir.). La sociologie du droit de Max Weber. Paris: Dalloz, 2006. p. 3-26.

SERRES, Michel. Le parasite. Paris: Hachette, 1997.

SMITH, Amy Erica. Covid vs. democracy: Brazil's populist playbook. Journal of Democracy, Washington, DC, v. 31, n. 4, p. 76-90, 2020.

SPECTOR, Céline. Souveraineté populaire et droits de l'homme: Rousseau, aux sources de l'autonomie et démocratie. Lumières, Bordeaux, n. 19, p. 49-61, 2002. (Dossier Les Lumières de Jürgen Habermas).

SUEUR, Jean-Jacques. Pierre Bourdieu, le droit et les juristes. La méprise. Droit et Société, Paris, n. 85, p. $725-753,2013$.

TARRAGONI, Federico. La science du populisme au crible de la critique sociologique: archéologie d'un mépris savant du peuple. Actuel Marx, Paris, n. 54, p. 56-70, 2013. 
TATE, Chester Neal; VALLINDER, Torbjörn. The global expansion of judicial power. New York: New York University Press, 1995.

TEIXEIRA, Anderson Vichinkeski. Ativismo judicial: nos limites entre racionalidade jurídica e decisão política. Revista Direito GV, São Paulo, v. 8, n. 1, p. 37-58, jan./jun. 2012.

TEUBNER, Gunther. Juridification: concepts, aspects, limits, solutions. In: TEUBNER, Gunther (ed.). Juridification of social spheres: a comparative analysis in the areas of labor, corporate, antitrust and social welfare law. Berlin: Walter de Gruyter, 1987. p. 3-48.

TOURAINE, Alain. Le retour de l'acteur: essai de sociologie. Paris: Fayard, 1984.

TOURAINE, Alain. Un nouveau paradigme: pour comprendre le monde aujourd'hui. Paris: Fayard, 2006.

VENTURA, Deisy de Freitas Lima; MARTINS, Jameson. Between Science and populism: the Brazilian response to COVID-19 from the perspective of the legal determinants of Global Health. Revista de Direito Internacional, Brasília, v. 17, n. 2, p. 66-83, 2020.

VERBICARO, Loiane Prado. Um estudo sobre as condições facilitadoras da judicialização da política no Brasil. Revista Direito GV, São Paulo, v. 4, n. 2, p. 389-406, jul./dez. 2008.

VERDIER, Raymond (dir.). Jean Carbonnier: l'homme et l'œuvre. Nanterre: Presses Universitaires de Paris Ouest, 2011.

VERDO, Geneviève. Pierre Rosanvallon, archéologie de la démocratie. Revue Historique, Paris, v. 623, n. 3, p. 693-720, 2002.

VERÍSSIMO, Marcos Paulo. A Constituição de 1988, vinte anos depois: suprema corte e ativismo judicial “à brasileira”. Revista Direito GV, São Paulo, v. 4, n. 2, p. 407-440, jul./dez. 2008.

VIANNA, Luiz Werneck et al. A judicialização da política e das relações sociais no Brasil. Rio de Janeiro: Revan, 1999.

VIANNA, Luiz Werneck; BURGOS, Marcelo Baumann; SALLES, Paula Martins. Dezessete anos de judicialização da política. Tempo Social, São Paulo, v. 19, n. 2, p. 39-85, nov. 2007.

VILLAS BÔAS FILHO, Orlando. Democracia: a polissemia de um conceito político fundamental. Revista da Faculdade de Direito da Universidade de São Paulo, São Paulo, v. 108, p. 651-696, jan./ dez. 2013.

VILLAS BÔAS FILHO, Orlando. A juridicização e a judiciarização enfocadas a partir da "sociologia política do direito" de Jacques Commaille. Revista Brasileira de Sociologia do Direito, Porto Alegre, v. 2, n. 2, p. 56-75, jul./dez. 2015.

VILLAS BÔAS FILHO, Orlando. A governança em suas múltiplas formas de expressão: o delineamento conceitual de um fenômeno complexo. Revista Estudos Institucionais, Rio de Janeiro, v. 2, n. 2, p. 670-706, 2016 a. 
VILLAS BÔAS FILHO, Orlando. A juridicização e o campo indigenista no Brasil: uma abordagem interdisciplinar. Revista da Faculdade de Direito da Universidade de São Paulo, São Paulo, v. 111, p. 339-379, jan./dez. 2016b.

VILLAS BÔAS FILHO, Orlando. O impacto da governança sobre a regulação jurídica contemporânea: uma abordagem a partir de André-Jean Arnaud. REDES: Revista Eletrônica Direito e Sociedade, Canoas, v. 4, n. 1, p. 145-171, maio 2016c.

VILLAS BÔAS FILHO, Orlando. Émile Durkheim e a análise sociológica do direito: a atualidade e os limites de um clássico. REDES: Revista Eletrônica Direito e Sociedade, Canoas, v. 5, n. 2, p. 229-250, nov. 2017.

VILLAS BÔAS FILHO, Orlando. O desenvolvimento dos estudos sociojurídicos: da cacofonia à construção de um campo de pesquisa interdisciplinar. Revista da Faculdade de Direito da Universidade de São Paulo, São Paulo, v. 113, p. 251-292, jan./dez. $2018 \mathrm{a}$.

VILLAS BÔAS FILHO, Orlando. O direito como revelador das transformações sociais contemporâneas: a abordagem sociopolítica de Jacques Commaille. Revista Direito GV, São Paulo, v. 14, n. 1, p. 268-277, jan./abr. 2018 b.

VILLAS BÔAS FILHO, Orlando. Por um delineamento conceitual da complexidade social: as experiências do Mercosul e do orçamento participativo na análise de André-Jean Arnaud sobre a governança. Novos Estudos Jurídicos, Itajaí, v. 23, n. 2, p. 491-520, maio/ago. 2018c.

VILLAS BÔAS FILHO, Orlando. A interdisciplinaridade nos estudos sociojurídicos: a experiência editorial da revista Droit et Société. Revista da Faculdade de Direito da Universidade de São Paulo, São Paulo, v. 114, p. 275-297, jan./dez. 2019a.

VILLAS BÔAS FILHO, Orlando. Ce que la sociologie juridique de l'Amérique Latine doit à AndréJean Arnaud: l'exemple de l'analyse de l'expérience du Mercosur dans le cadre de son étude de la gouvernance. In: CAPELLER, Wanda; COMMAILLE, Jacques; ORTIZ, Laure (dir.). Repenser le droit: hommage à André-Jean Arnaud. Paris: LGDJ, 2019b. p. 101-110.

VILLAS BÔAS FILHO, Orlando. Desafios da pesquisa interdisciplinar: as ciências sociais como instrumentos de "vigilância epistemológica" no campo dos estudos sociojurídicos. Revista Estudos Institucionais, Rio de Janeiro, v. 5, n. 2, p. 530-558, maio/ago. 2019c.

VILLAS BÔAS FILHO, Orlando. Direito e sociedade na obra de Émile Durkheim: bases de uma matriz sociológica para os estudos sociojurídicos. São Paulo: Editora Mackenzie, 2019d.

VILLAS BÔAS FILHO, Orlando. A "jurística” de Henri Lévy-Bruhl e a construção dos estudos sociojurídicos na França. Prisma Jurídico, São Paulo, v. 19, n. 1, p. 23-39, jan./jun. 2020.

WEFFORT, Francisco C. O populismo na política brasileira. 5. ed. Rio de Janeiro: Paz e Terra, 2003. 
WHITE, Stephen K. Reason, modernity, and democracy. In: WHITE, Stephen K. (ed.). The Cambridge companion to Habermas. Cambridge: Cambridge University Press, 1999. p. 3-16. 